\title{
Recent Advances in the Regioselective Synthesis of Indoles via C-H Activation/Functionalization
}

\author{
Inder Kumar $\ddagger \mathbf{a}, \mathrm{b}$ \\ Rakesh Kumar $\ddagger$ a,b \\ Upendra Sharma*a,b \\ a Natural Product Chemistry and Process Development Division, \\ CSIR-Institute of Himalayan Bioresource Technology, Palampur, \\ Himachal Pradesh, 176061, India \\ b Academy of Scientific and Innovative Research, CSIR-IHBT, \\ Palampur, Himachal Pradesh 176061, India \\ upendra@ihbt.res.in \\ upendraihbt@gmail.com \\ $\ddagger$ These authors contributed equally to this review.
}

\begin{abstract}
Received: 25.01.2018
Accepted after revision: 05.03.2018

Published online: 28.05 .2018

DOI: 10.1055/s-0037-1609733; Art ID: ss-2018-m0041-r

Abstract Indole is an important heterocyclic motif that occurs ubiquitously in bioactive natural products and pharmaceuticals. Immense efforts have been devoted to the synthesis of indoles starting from the Fisher indole synthesis to the recently developed $\mathrm{C}-\mathrm{H}$ activation/functionalization-based methods. Herein, we have reviewed the progress made on the regioselective synthesis of functionalized indoles, including 2-substituted, 3-substituted and 2,3-disusbstituted indoles, since the year 2010 .

1 Introduction

2 Metal-Catalyzed Synthesis of 2-Substituted Indoles

3 Metal-Catalyzed Synthesis of 3-Substituted Indoles

$4 \quad$ Metal-Free Synthesis of 3-Substituted Indoles

5 Metal-Catalyzed 2,3-Disubstituted Indole Synthesis

5.1 Metal-Catalyzed Intramolecular 2,3-Disubstituted Indole Synthesis

5.2 Metal-Catalyzed Intermolecular 2,3-Disubstituted Indole Synthesis

6 Metal-Free 2,3-Disubstituted Indole Synthesis

6.1 N-Protected 2,3-Disubstituted Indole Synthesis

6.2 N-Unprotected 2,3-Disubstituted Indole Synthesis

7 Applications

8 Summary and Outlook
\end{abstract}

Key words indoles, $\mathrm{C}-\mathrm{H}$ activation, catalytic, metal-free, natural products

\section{Introduction}

The indole moiety is one of the key heterocyclic motifs that occur ubiquitously in bioactive natural products, pharmaceuticals, agrochemicals, fragrances, pigments and in optoelectronic functional materials. ${ }^{1}$ Examples of indolecontaining biologically active compounds include arbidol (1), indomethacin (2), PD-0298029 (3), reserpine (4), iprindole (5) and dimebon (6) (Figure 1). ${ }^{2}$ The synthesis of indole

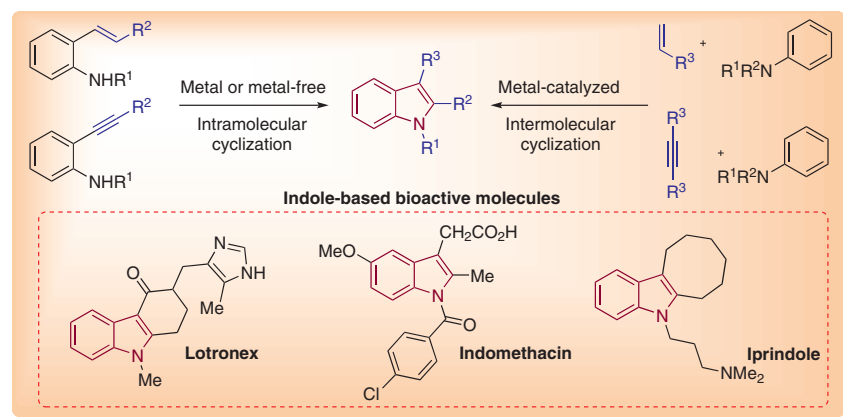

and its derivatives has been the topic of research for over 130 years, and a variety of classical methods have been discovered during this time including: Fisher, Bischler, Gassmann and Batcho-Leimgruber syntheses of indoles. ${ }^{3}$ However, these methods have several limitations, for example, in the case of the Fischer indole synthesis, toxic hydrazine hydrate is required along with highly acidic conditions and overall, the functional group tolerance is moderate. Over the last two decades, various methodologies have been developed to overcome the existing limitations of the synthesis of indole derivatives. Several metal-catalyzed and metal-free approaches have been reported for the synthesis of indole derivatives. Different research groups have compiled the literature on the synthesis of indoles with focus on diverse aspects. ${ }^{4}$
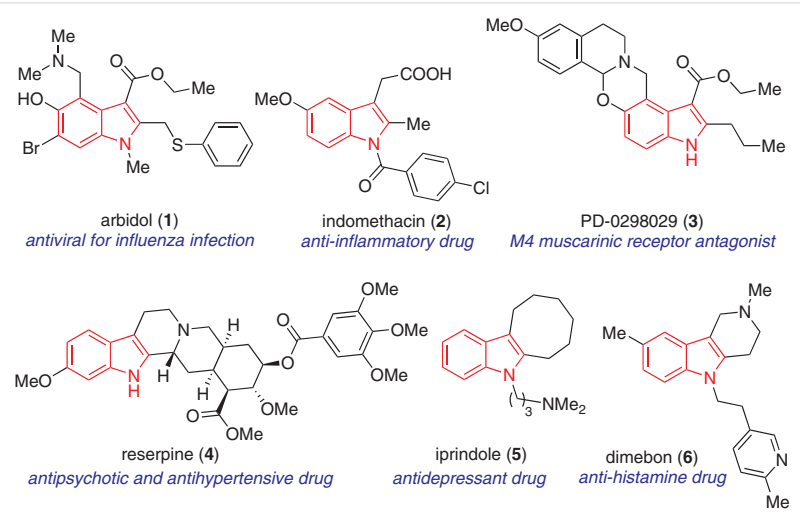

Figure 1 Selected examples of bioactive indoles

The present review focuses on the recent advancements in the regioselective synthesis of substituted indole derivatives, covering the literature from 2011 to present. 


\section{Metal-Catalyzed Synthesis of 2-Substitut- ed Indoles}

For many alkaloids and pharmacologically significant compounds, 2-substituted indoles are important intermediates. Many research groups have focused their work on the synthesis of 2-functionalized indoles, mainly through transition-metal-catalyzed $\mathrm{C}-\mathrm{H}$ bond activation strategies. Furthermore, photocatalytic approaches have also been used for their synthesis.

In 2012, Maity et al. reported on the ruthenium(II)-catalyzed photocatalytic synthesis of $N$-arylindoles 8 using an $18 \mathrm{~W}$ white-light LED (Scheme 1$).{ }^{5}$ An appealing methodology involving oxidative $\mathrm{C}-\mathrm{N}$ bond formation leads to the synthesis of indoles under aerobic oxidation conditions. However, the role of the $p$-alkoxyphenyl group and the silica gel used in the reaction was not clear, the $p$-alkoxyphenyl group on the nitrogen atom being essential for the reaction. This methodology is applicable to a broad range of substrates giving the desired indoles in moderate to good yields. Electron-donating and electron-withdrawing groups on the aryl ring were well tolerated. Alkenes with different substituents such as alkanes, alkenes, arenes and furans gave the desired products in good yields and the method was also applicable for the synthesis of 2,3-disubstituted indoles.

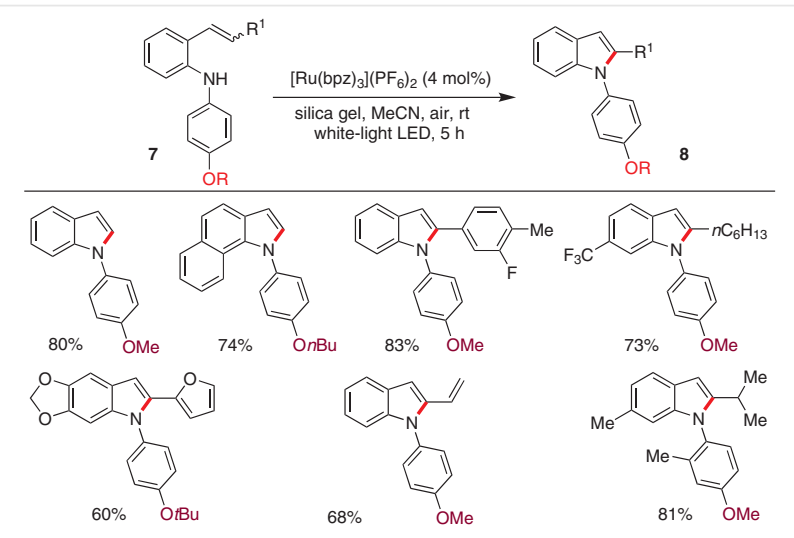

Scheme 1 Ruthenium(II)-catalyzed intramolecular photocatalytic synthesis of $\mathrm{N}$-arylindoles

The proposed catalytic cycle for this transformation involves conversion of the amine into a nitrogen-centered radical cation using photoexcited $\left[\mathrm{Ru}(\mathrm{bpz})_{3}\right]\left(\mathrm{PF}_{6}\right)_{2}$, followed by the generation of benzylic radical I. Oxidation of the benzylic radical resulted in benzylic cation II, which finally undergoes aromatization to form the indole ring (Scheme 2).

\section{Biographical Sketches}

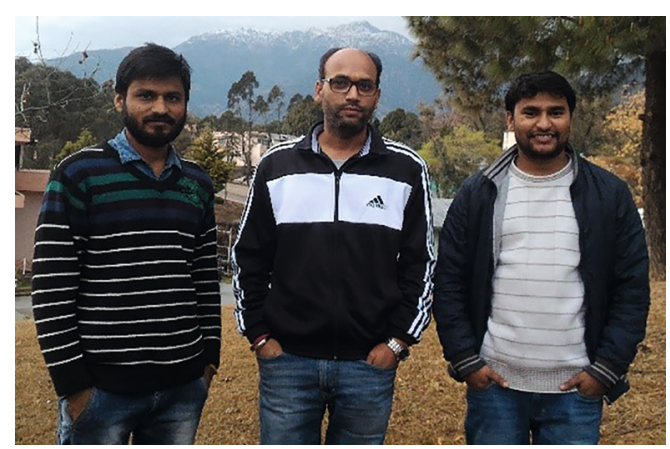

Inder Kumar (right) graduated in Science from Himachal Pradesh University, Shimla, in 2011. He obtained his M.Sc. (2013) and M.Phil. (2014) in Chemistry from HPU, Shimla, and then joined the group of Dr. Sharma in 2015 to undertake doctoral studies. Currently, he is working on first row transitionmetal-catalyzed $\mathrm{C}-\mathrm{H}$ activation/functionalization.

Rakesh Kumar (left) graduated in Science from Himachal Pradesh University, Shimla, in
2011. He completed his M.Sc. in organic chemistry at HPU, Shimla, in 2013, before joining Dr. Sharma's group in 2015 for his doctoral studies. Currently, he is working on transition-metal-catalyzed $\quad \mathrm{C}-\mathrm{H}$ activation/functionalization.

Upendra Sharma (center) is currently a scientist and assistant professor at CSIRIHBT, Palampur. He completed his Ph.D. on natural product chemistry and metal-phthalocyanine-catalyzed reactions in the fall of
2012, under the supervision of Dr. Bikram Singh. He then joined Prof. Debabrata Maiti's group at IIT Bombay, India as a postdoctoral researcher. In March 2014, Dr. Sharma continued his postdoctoral studies with Prof. Sukbok Chang at KAIST, Daejeon, Korea. In September 2014, he started his independent research as a Scientist at NPC\&PD Division, CSIR-IHBT, Palampur, India. His research is focused on transition-metal-catalyzed $\mathrm{C}-\mathrm{H}$ activation/functionalization and natural product chemistry. 
<smiles>c1ccc2c(c1)CCCN2</smiles>

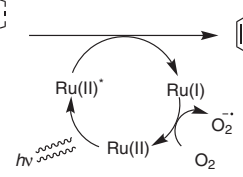<smiles>C1=Cc2c3c([nH]c2=C1)=NC=N3</smiles>
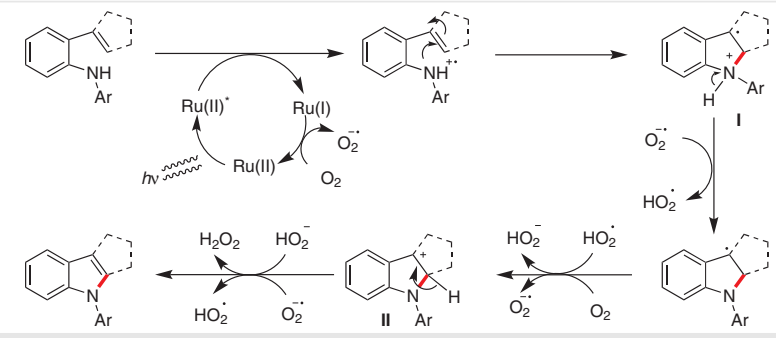

Scheme 2 Proposed mechanism for the photocatalytic synthesis of $\mathrm{N}$ arylindoles

The involvement of benzylic carbocation II in the visible-light-mediated reaction was further supported by the formation of 2,3-disubstituted indole $\mathbf{1 0}$ from gem-styrylaniline 9 through a 1,2-carbon shift under the optimized reaction conditions (Scheme 3 ).

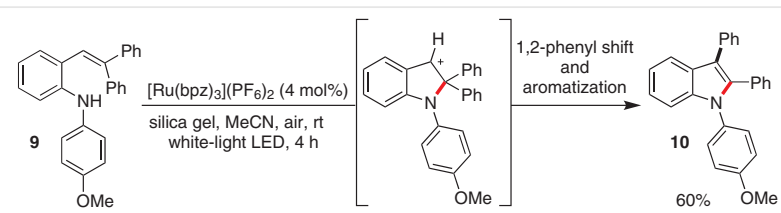

Scheme 3 Proof for the involvement of a benzylic carbocation in visible-light-mediated reaction

In 2012, Yoshikai et al. reported the palladium-catalyzed cyclization reaction of $\mathrm{N}$-arylamines $\mathbf{1 1}$ forming C-2 substituted indoles 12 via the oxidative linkage of two $\mathrm{C}-\mathrm{H}$ bonds (Scheme 4). ${ }^{6}$ The methodology gave rapid, atom-economic and regioselective access to various indole derivatives under mild reaction conditions using molecular oxygen as the solitary oxidant. Inexpensive and readily available anilines and ketones were used to prepare imines, which were cyclized to form indole moieties; the reaction was also successfully carried out on gram scale. Indole derivatives with heterocyclic substituents such as pyridine and furan at the $\mathrm{C}-2$ position were obtained in excellent

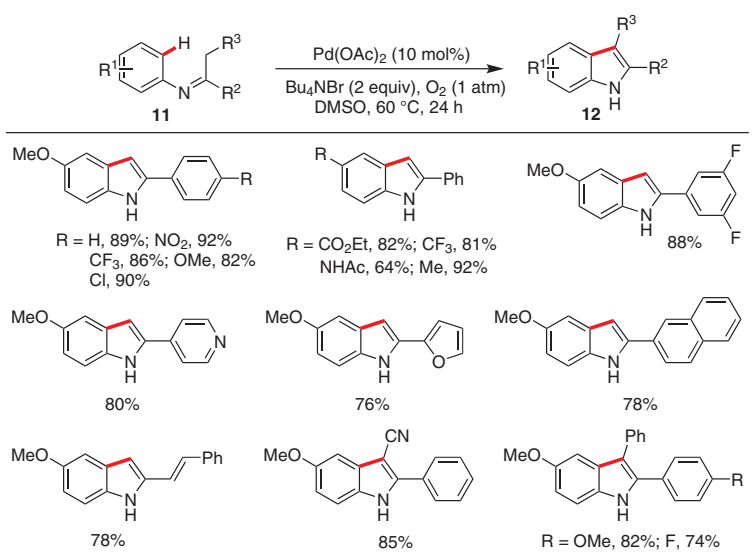

Scheme 4 Palladium(II)-catalyzed intramolecular synthesis of indoles yields. This mode of cyclization was also applicable for the synthesis of 2,3-diarylindoles, overcoming the difficulties of the Larock- and Fagnou-type annulation reactions.

The authors observed a KIE value of 5.2 indicating a concerted metalation-deprotonation mechanism. The plausible mechanism for this transformation involves a $\mathrm{Pd}(\mathrm{II}) / \mathrm{Pd}(0)$ redox process proceeding via electrophilic attack of $\mathrm{Pd}(\mathrm{OAc})_{2}$ on enamine III generated via tautomerization (Scheme 5).

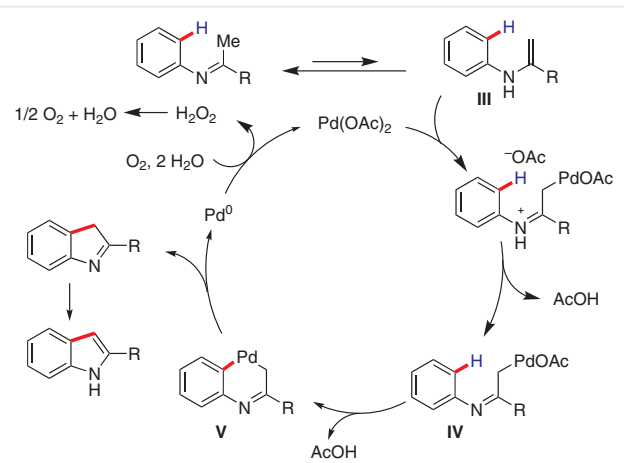

Scheme 5 Proposed mechanism for the palladium(II)-catalyzed intramolecular synthesis of indoles

This is followed by elimination of AcOH to give $\alpha$-palladated imine intermediate IV, which after intramolecular aromatic $\mathrm{C}-\mathrm{H}$ palladation gave palladacycle $\mathbf{V}$, thus forming a $3 \mathrm{H}$-indole and $\operatorname{Pd}(0)$ after reductive elimination. The $3 \mathrm{H}$-indole undergoes tautomerization rapidly to give the indole, while combination of molecular oxygen and $\mathrm{AcOH}$ oxidizes $\operatorname{Pd}(0)$ back to $\mathrm{Pd}(\mathrm{II})$, thus completing the catalytic cycle.

In 2012, Yoshiji Takemoto and co-workers synthesized the indole skeleton $\mathbf{1 5}$ using a palladium-catalyzed cascade process involving isocyanide 13 insertion and benzylic $\mathrm{C}\left(\mathrm{sp}^{3}\right)-\mathrm{H}$ activation (Scheme 6). ${ }^{7}$ This represents the first report on the use of a combination of palladium-catalyzed isocyanide insertion and $\mathrm{C}\left(\mathrm{sp}^{3}\right)-\mathrm{H}$ activation for the synthesis of heterocycles. The synthesis of different 2-arylindoles can be achieved by changing the coupling partners and represents a unique palladium-catalyzed strategy for $\mathrm{C}-\mathrm{C}$ bond formation between the 2- and 3-position of indole. The slow addition of the isocyanide was adopted to avoid catalyst deactivation. Using different aryl halides 14 as coupling partners resulted in the synthesis of a range of indoles with different substituents. Electron-donating and electron-withdrawing groups at the para position of aryl iodides were well tolerated, whereas the introduction of a methyl group at the ortho position led to a lower yield of the final product. Bromobenzene gave the desired product in good yield, but chlorobenzene did not react under these conditions. Diethylphenyl isocyanide and 2,4-dimethylphenyl isocyanide were also found to unsuitable under the developed conditions. 


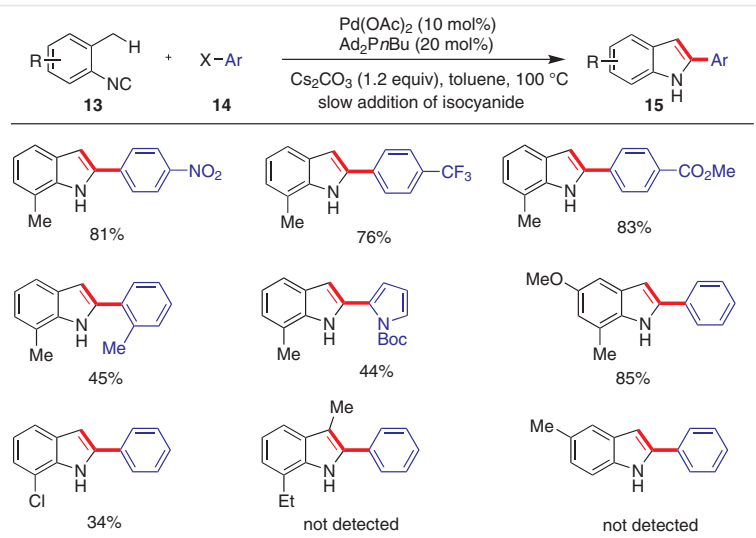

Scheme 6 A palladium(II)-catalyzed cascade process for the synthesis of 2 -substituted indoles

In 2013, Zhang's group delineated the synthesis N-protected C-2 functionalized indoles 18 through combined gold/zinc catalysis using $\mathrm{N}$-arylhydroxamic acids/ $\mathrm{N}$-hydroxycarbamates $\mathbf{1 6}$ and alkynes $\mathbf{1 7}$ (Scheme 7). ${ }^{8}$

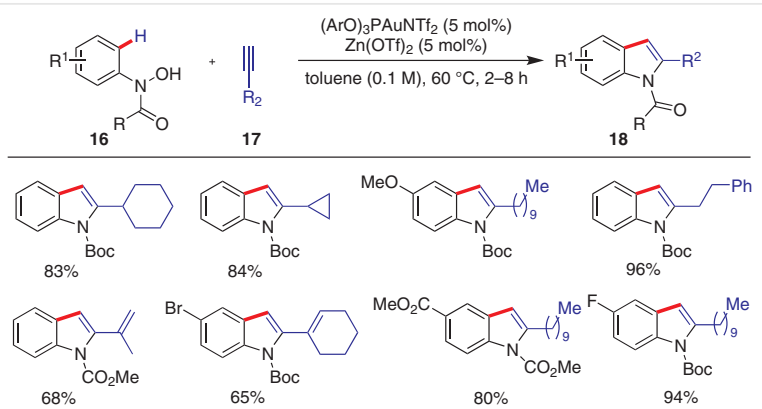

Scheme 7 Gold-catalyzed synthesis of 2-susbtituted indoles

The limitations associated with the well-known Fischer indole synthesis and Bartoli reaction, such as strong acidic conditions, regioselectivity, tolerance to sensitive moieties like the Boc protecting group and limited substrate scope, were overcome by employing this synthetic strategy. Indoles with different functional groups, such as aliphatic alkanes, cyclohexane, and cyclopropane, were easily prepared.

Indoles with a methyl group at the C-2 position were favored with high regioselectivity, possibly because of less steric hindrance. The authors proposed that the pathway involves activation of the hydroxamic acid or a related substrate via zinc chelate formation (Scheme 8). Gold-activated alkyne VI was then effectively attacked by the more O-nucleophilic zinc chelate VII, which upon subsequent protodeauration formed a precursor for 3,3-sigmatropic rearrangement. Finally, the Lewis acid Zn(OTf $)_{2}$-assisted cyclodehydration leads to the desired indole product.

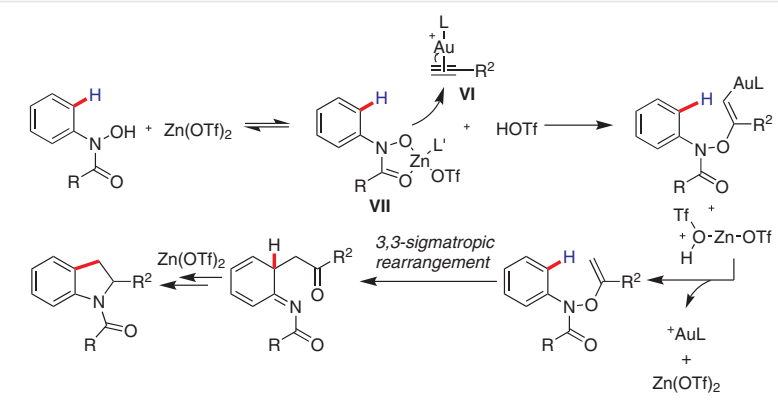

Scheme 8 Proposed mechanism for the gold-catalyzed synthesis of indoles

In 2013, Cossy's group carried out the synthesis of 1,2disubstituted indoles from benzyl alcohols through an iridium-catalyzed hydrogen atom transfer process (Scheme 9). ${ }^{9}$ $p$-Benzoquinone was used as the co-oxidant in the reaction.

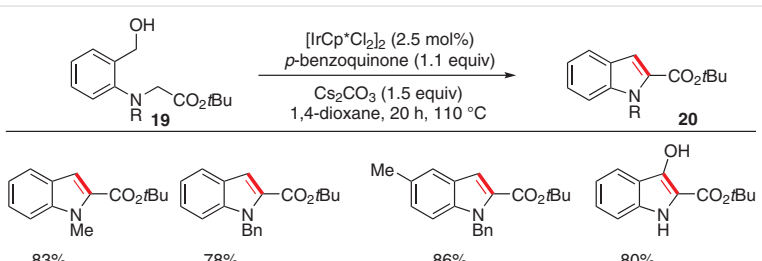

$83 \%$

$78 \%$

$86 \%$

$80 \%$

Scheme 9 Iridium-catalyzed synthesis of 2-susbtituted indoles

The proposed mechanism of the reaction involves the conversion of the alcohol into an aldehyde VIII through hydrogen atom transfer involving the iridium catalyst. $p$-Benzoquinone regenerates the catalyst through oxidation. The intermediate VIII then undergoes intramolecular cyclization in the presence of a base to give IX, which may aromatize with removal of water to give the 1,2-disubstituted indole. Removal of the tosyl protecting group from IX in the presence of the base generates $\mathbf{X}$, which upon further rearrangement gives the expected indole (Scheme 10).

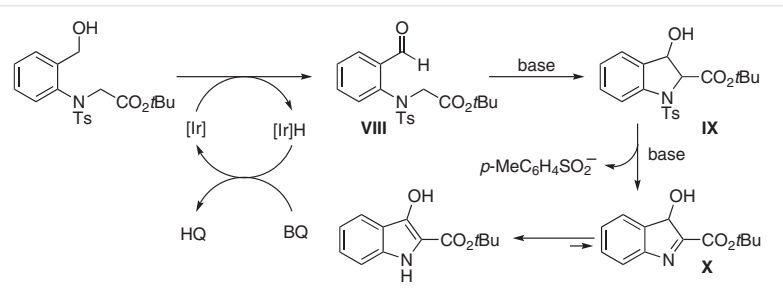

Scheme 10 Predicted mechanism for the synthesis of 2-susbtituted indoles

In 2013, Kiruthika and Perumal disclosed an efficient strategy for the synthesis of 2-amidoindoles 23 through in situ generated ynamides followed by hydroamidation 
(Scheme 11). ${ }^{10}$ The method involves the intermolecular coupling of gem-dibromovinylanilide $\mathbf{2 1}$ and sulfonamides 22 using $\mathrm{Cu}(\mathrm{I})$ iodide as the catalyst.

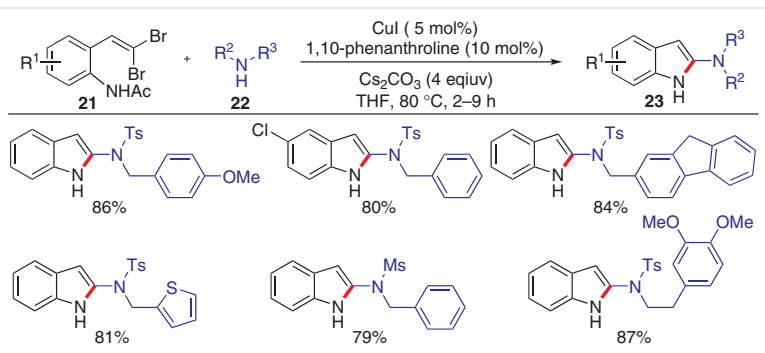

Scheme 11 Cul-catalyzed synthesis of 2-susbtituted indoles

Acetamide derivatives $\mathbf{2 1}$ were used as the product yield was low in the case of an aniline derivative. The presence of an electron-withdrawing group such as tosyl or mesitylsulfonyl was essential on the nitrogen of $\mathbf{2 2}$ for the reaction to progress.

The plausible mechanism for the reaction involves the oxidative insertion of the more reactive trans $\mathrm{C}-\mathrm{Br}$ bond of 21 into XI to furnish intermediate XII (Scheme 12). Reductive elimination followed by dehydrobromination in the presence of a base provides the ynamide. Further base-promoted intramolecular hydroamidation and deacetylation results in the formation of the desired 2-substituted indole.

May and co-workers reported the copper-catalyzed synthesis of $\mathrm{N}$-substituted indoles $\mathbf{2 5}$ from the corresponding primary amines and carbonyl compounds $\mathbf{2 4}$ through a two-step, one-pot approach (Scheme 13). ${ }^{11}$ The authors optimized the reaction conditions separately for imine $\mathbf{2 6}$ formation and cyclization.

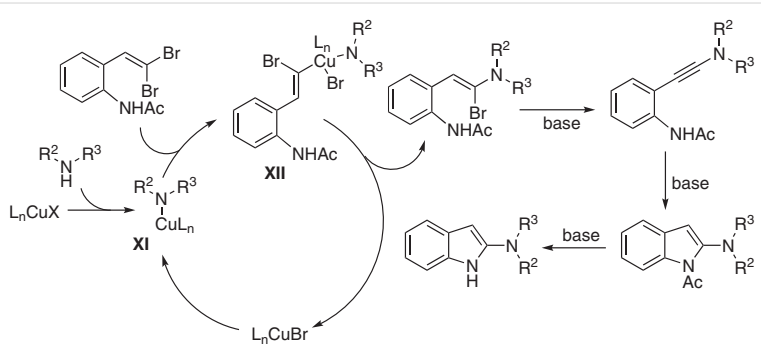

Scheme 12 Plausible catalytic cycle

Imine formation was efficient in benzene whereas for cyclization DMF was used as the reaction medium. The method was applicable for anilines, benzylamines, and aliphatic amines providing the desired indoles in good yields. Further, diversified 3- or 2,3-substituted indoles could also be synthesized through this method by using $\alpha$-aryl or cyclic ketones, respectively.

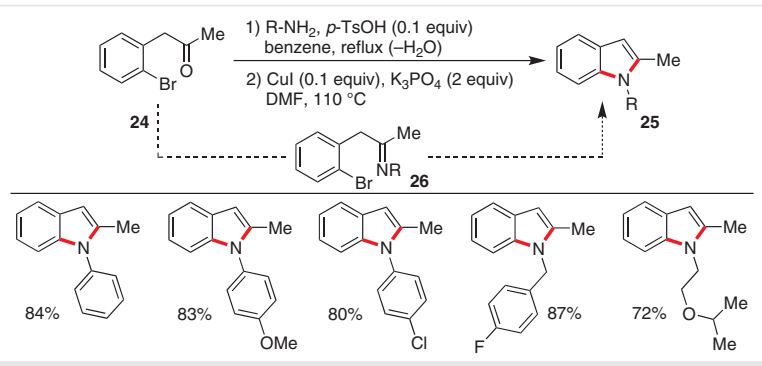

Scheme $13 \mathrm{Cu}(\mathrm{I})$-catalyzed synthesis of indoles from primary amines

Yu et al. reported the synthesis of functionalized indoles 29 through palladium-catalyzed, copper-mediated oxidative annulations of in situ generated enones with $\mathrm{N}$-substituted pyrroles 27 (Scheme 14). ${ }^{12}$ Various 3-chloroalkyl ketones and pyrrole derivatives were well tolerated under the reported reaction conditions providing the corresponding indole products in moderate to good yields. Although the method was applicable for the synthesis of multi-substituted indoles, the reaction conditions were very harsh which limits the scope of the reaction on industrial scale. The authors proposed that the reaction proceeds through a sequence of dehydrochlorination, $\mathrm{C}-\mathrm{H}$ activation, Diels-Alder cycloaddition and dehydrogenative aromatization.

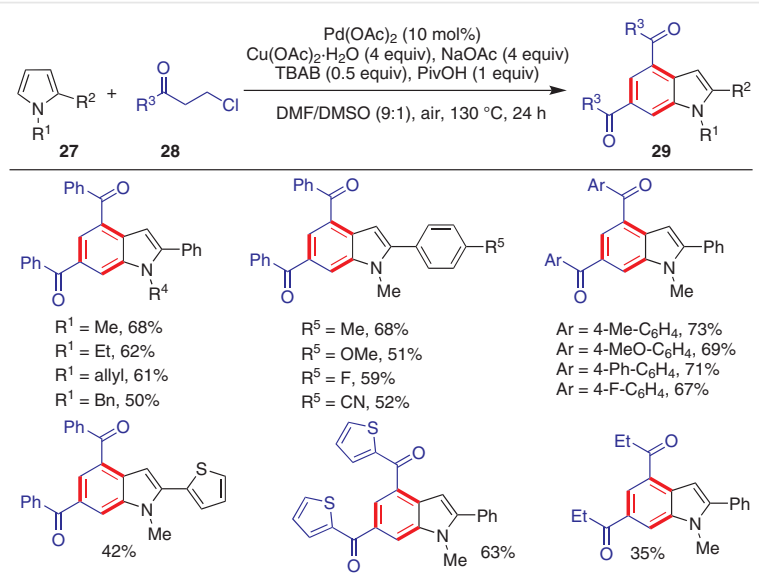

Scheme $14 \mathrm{Pd}(\mathrm{II})$-catalyzed, Cu(II)-mediated synthesis of indoles through annulations of enones with $\mathrm{N}$-substituted pyrroles

Otani and co-workers examined the Lewis acid promoted cycloisomerization of $\mathrm{N}$-imidoyl-2-alkynylanilines $\mathbf{3 0}$ with substituents such as alkyl or aryl (Scheme 15). ${ }^{13}$ They showed the formation of indole derivatives via a 5-endo-dig cyclization mode.

The electronic effects of the $\mathrm{R}^{1}$ substituent affect the cyclization selectivity; the plausible mechanism for the cyclization involves the Ag-alkyne complex species XIII in the stereoelectronically favorable 5-endo-dig mode of cyclization (Scheme 16). 


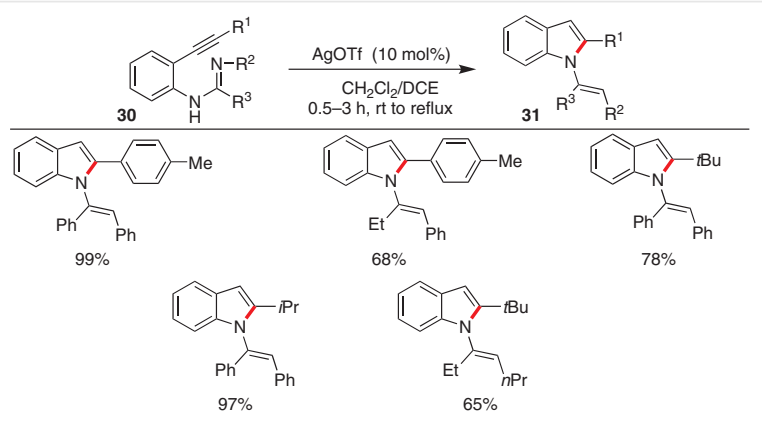

Scheme 15 Silver(I)-promoted intramolecular synthesis of indoles

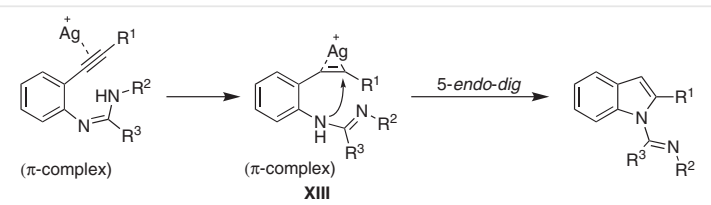

Scheme 16 Proposed pathway for the silver(I)-promoted intramolecular synthesis of indoles

In 2015, Ghorai's group developed a two-step, one-pot strategy to synthesize 2-alkylindoles $\mathbf{3 3}$ via thiophenol-mediated regioselective ring-opening of 2-(2-haloaryl)-3-alkyl- $\mathrm{N}$-tosylaziridines 32, followed by copper-mediated intramolecular $\mathrm{C}-\mathrm{N}$ cyclization with subsequent aromatization by thiophenol elimination (Scheme 17). ${ }^{14}$ This method overcomes the limitation of the synthesis of halogenated 2alkylindoles, which otherwise were impossible to synthesize by alpha-lithiation of indoles. ${ }^{15}$ Various halogenated indoles were prepared in good to excellent yields using either a cis/trans mixture or mono-substituted aziridines, though trans disubstituted aziridines were found to be more reactive than the cis isomer due to steric reasons.

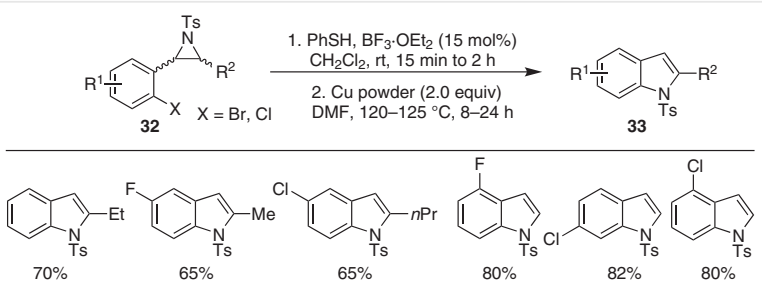

Scheme 17 Synthesis of 2-alkylindoles

The mechanism of the reaction possibly follows the copper-powder-mediated $\mathrm{C}-\mathrm{N}$ cyclization as described in Ghorai's earlier report, ${ }^{16}$ with the final aromatization step involving $\mathrm{Cu}(\mathrm{I})$-mediated desulfonylation via the formation of cationic thioether intermediate XIV (Scheme 18).

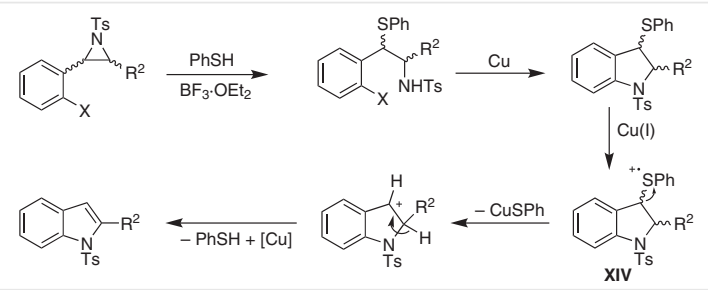

Scheme 18 Reaction pathway for the Cu-mediated C-N cyclization

\section{Metal-Catalyzed Synthesis of 3-Substitut- ed Indoles}

The regioselective synthesis of C-3 functionalized indoles $\mathbf{3 6}$ and $\mathbf{3 7}$ from the aryl azides $\mathbf{3 4}$ having exceptional reactivity toward alkynes $\mathbf{3 5}$ was reported by Gallo's group in 2014 (Scheme 19). ${ }^{17}$ This ruthenium-porphyrin-complex-catalyzed methodology furnished indoles instead of triazoles and is attractive for the synthesis of C-3 functionalized indoles having electron-withdrawing substituents on the azide fragment. Only C-3 functionalized indoles were obtained in high yield with aromatic terminal alkynes. The steric hindrance caused by the alkynes was responsible for the low reaction yield observed for C-2 functionalized indoles when using internal alkynes as coupling partners. Also, aliphatic alkynes were not suitable for indole synthesis under the reported conditions. It was observed that when $\mathrm{R}^{1}=\mathrm{R}^{3}$, the reaction yield was high, while with different substituents the product was obtained in a lower yield, and when only one substituent was present on the benzene ring of the azide, the indole yield was lower. The proposed mechanism for this reaction involves initially the formation of $\mathrm{N}$-substituted- $1 \mathrm{H}$-azirine intermediate $\mathbf{X V}$. The polarization of a sp ${ }^{2} \mathrm{C}-\mathrm{H}$ aromatic bond ortho to the electron-withdrawing group assists a hydrogen transfer reaction, which is responsible for the indole cyclization (Scheme 20).

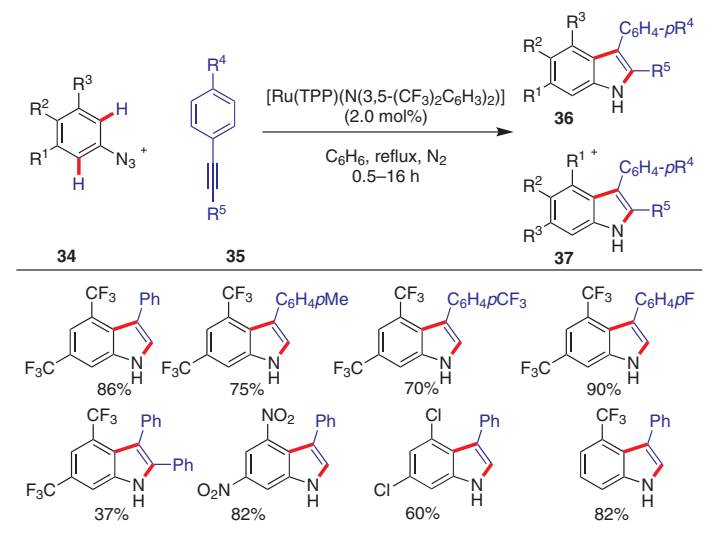

Scheme 19 Ruthenium-catalyzed regioselective synthesis of indoles 


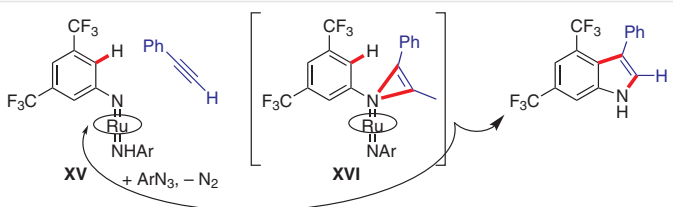

Scheme 20 Proposed mechanism for the synthesis of C-3 functionalized indoles

Choi et al. reported the Co-Rh heterobimetallic nanoparticle-charcoal-catalyzed reductive cyclization of 2-(2-nitroaryl)-acetonitriles $\mathbf{3 8}$ to give indole motifs $\mathbf{3 9}$ (Scheme 21). ${ }^{18}$ The catalyst can be reused more than ten times without any loss of activity and the developed strategy was also applicable for gram-scale reactions. Under the optimized conditions, several functional groups were tolerated affording high product yields.

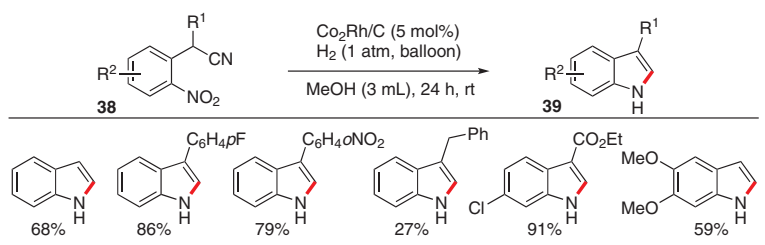

Scheme 21 Heterobimetallic nanoparticle-charcoal-catalyzed synthesis of 3-susbtituted indoles

\section{Metal-Free Synthesis of 3-Substituted In- doles}

Recently, Ito et al. developed a novel transition-metalfree reductive Fischer indole synthesis by reacting easily available $N$-aryl hydrazones 40 with tert-butyl iodide as a source of anhydrous $\mathrm{HI}$, which acts as Bronsted acid as well as a reducing agent (Scheme 22). ${ }^{19}$ The developed method

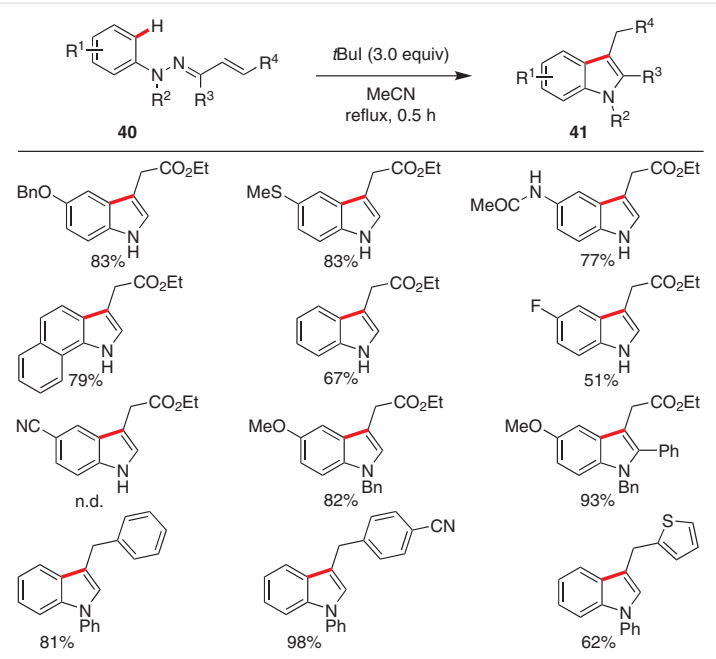

Scheme 22 Fischer indole synthesis of C-3 substituted indoles represents the first ever report on a 1,4-reduction of a conjugated hydrazone with a sequential Fischer indolization reaction of an in situ generated enamine, and can be applied to the synthesis of biologically active C-3 substituted indole derivatives. The role of the solvent was crucial for the transformation as only polar solvents were able to give the desired product.

Various substituted $\mathrm{N}$-aryl hydrazones were selectively converted into the corresponding indoles 41 , including substrates with an electron-donating methoxy group at the para position of the benzene ring, amide, halogen atoms, etc., or substrates without substituents. As electron-withdrawing groups were not suitable for the 3,3-sigmatropic rearrangement step, an indole with a cyano group at the C5 position was not observed under these conditions. Heterocyclic, electron-donating and electron-withdrawing groups at the $\mathrm{R}^{4}$ position were well tolerated.

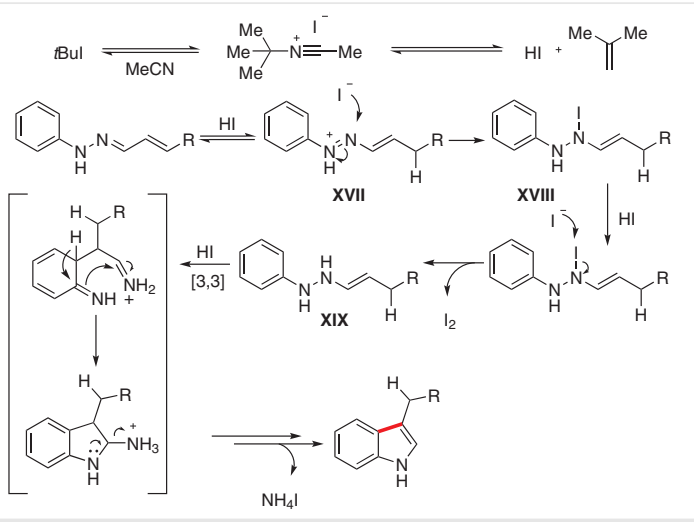

Scheme 23 Proposed mechanism for the metal-free synthesis of 3substituted indoles

A plausible mechanism for this transformation involves the initial attack of tert-butyl iodide at MeCN to give $\mathrm{HI}$, which then regioselectively protonates the $\mathrm{N}$-aryl hydrazone to give azonium ion XVII. The addition of an iodide anion to the azonium ion converts it into another intermediate XVIII, which was further reduced by HI to give enamine XIX. After the 3,3-sigmatropic rearrangement of the enamine, subsequent cyclization and aromatization with the loss of ammonium iodide gives the desired indole (Scheme 23).

\section{Metal-Catalyzed 2,3-Disubstituted Indole Synthesis}

Over the last two decades, many new methodologies have been reported for the synthesis of indole derivatives to overcome the existing limitations. Various metal-catalyzed as well as metal-free approaches have been developed for the synthesis of 2,3-disubstituted indole derivatives. ${ }^{20}$ 


\subsection{Metal-Catalyzed Intramolecular 2,3-Disubsti- tuted Indole Synthesis}

Considering the high importance of the 2,3-disubstituted indole structural motif in the pharmaceutical industry and in medicinal chemistry, a large number of efforts have been made in the last few years to develop simple and costeffective methods for their synthesis.

In 2010, Cacchi's group disclosed the synthesis of 2,3disubstituted indoles $\mathbf{4 4}$ from arenediazonium tetrafluoroborates $\mathbf{4 2}$ and 2-alkynyltrifluoroacetanilides $\mathbf{4 3}$ using a palladium catalyst. The method showed excellent functional group tolerance both in the alkyne and the arenediazonium component, including halo substituents. Arenediazonium salts containing ortho substituents gave the corresponding products in good to high yields (Scheme 24). ${ }^{21}$

This reaction proceeds through an iododediazonization step (Scheme 25, path a) followed by oxidative addition to $\operatorname{Pd}(0)$ to afford the arylpalladium iodide $\mathbf{X X}$ that coordinates with the alkyne to give palladium complex XXI. A subsequent intramolecular aminopalladation generates $\sigma$ intermediate XXII, which via reductive elimination and hydrolysis gives the desired product. ${ }^{21}$ Alternative mechanisms, which appear less likely, involve the formation of arylpalladium iodides through the reaction of $\sigma$-arylpalladium cation XXIII with iodide anions (Scheme 25, path b).

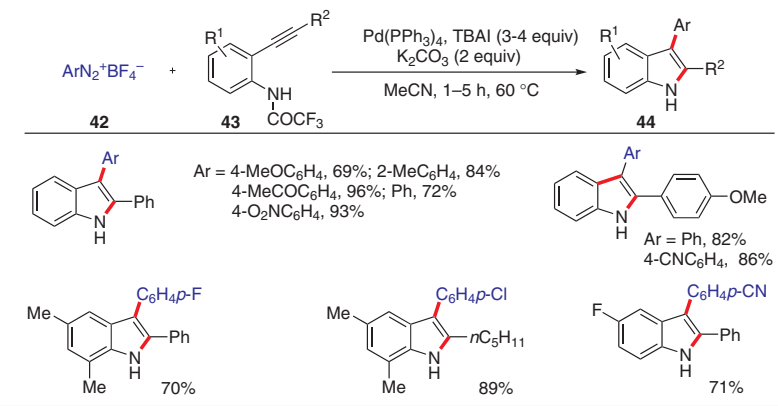

Scheme 24 Synthesis of 2,3-disubstituted indoles

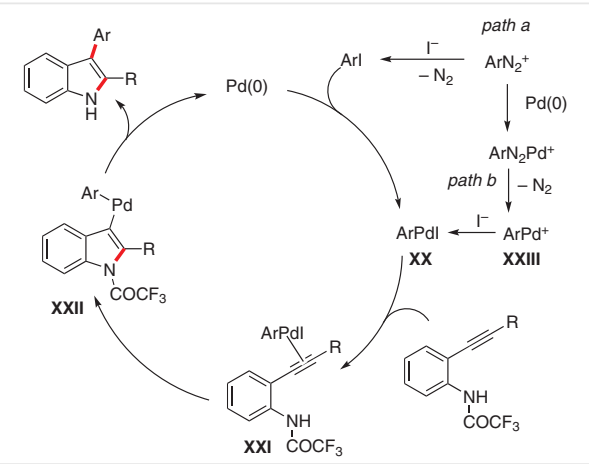

Scheme 25 A plausible catalytic cycle for the synthesis of 2,3-disubstituted indoles
In 2011, the Waser group reported the one-pot synthesis of 3-silylethynyl indoles $\mathbf{4 7}$ via the cyclization of 2-alkynylanilines $\mathbf{4 5}$ using $\mathrm{NaAuCl}_{4}$ as the catalyst. The intermediate indoles $\mathbf{4 6}$ underwent C3-alkynylation with $\mathrm{AuCl}$ and TIPS-EBX to afford the products $\mathbf{4 7}$. This reaction was also applicable for unprotected anilines, demonstrated good functional group tolerance and was very easy to carry out (Scheme 26). ${ }^{22}$

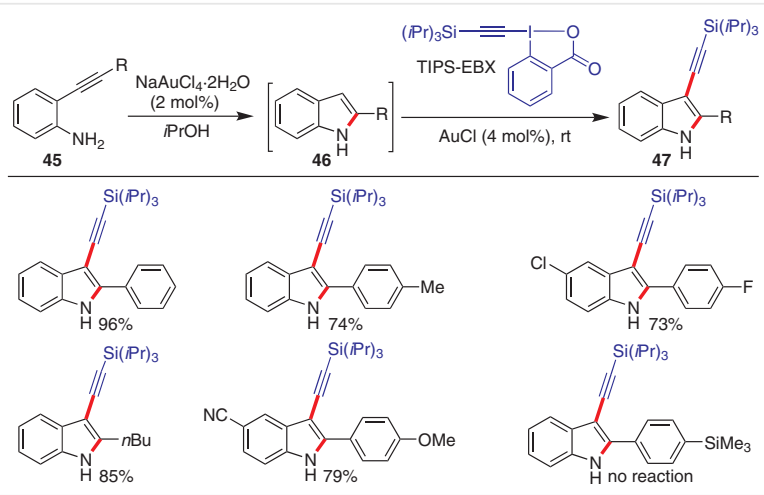

Scheme 26 Gold-catalyzed synthesis of 2-substituted 3-silylethynyl indoles from unprotected $o$-alkynylanilines

Ghorai and co-workers reported the palladium-catalyzed synthesis of 3-substituted 2-benzylindoles $\mathbf{4 9}$ through oxidative annulations of $\boldsymbol{o}$-allylanilines $\mathbf{4 8}$ with $\mathrm{O}_{2}$ as the oxidant (Scheme 27). ${ }^{23}$ The same authors also reported the one-pot synthesis of indoles from $\mathbf{4 8}$, which are prepared from aniline and substituted allyl alcohols using an oxorhenium catalytic system. ${ }^{23}$ The reported catalytic system provided good regioselectivity and was amenable to a broad substrate scope with high functional group tolerance.

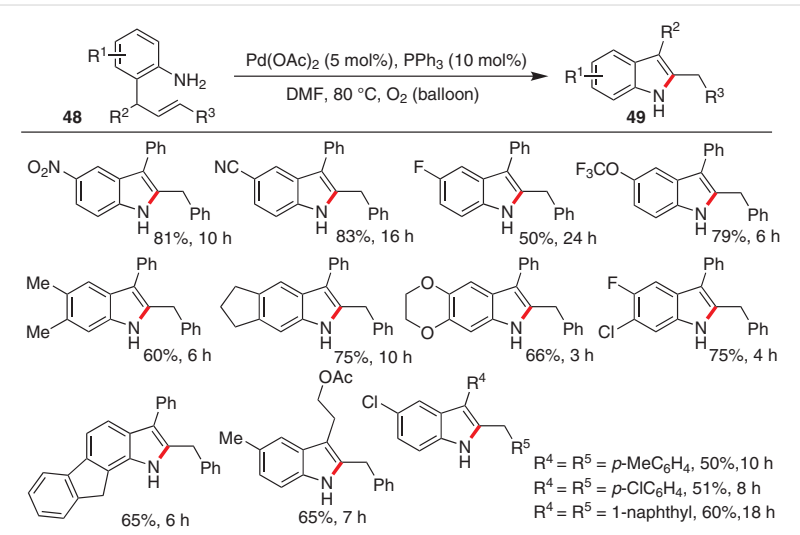

Scheme 27 Palladium-catalyzed intramolecular synthesis of 3-substituted 2-benzylindoles from 0 -allylanilines

The catalytic cycle of this reaction was initiated by palladium-catalyzed aminopalladation of the 2-allylaniline via an intramolecular 5-exo-trig cyclization to generate intermediate XXIV, followed by $\beta$-hydride elimination to form 
intermediate $\mathbf{X X V}$. Isomerization of this intermediate gives the final product 49 and $\mathrm{O}_{2}$ oxidizes $\mathrm{Pd}(0)$ to regenerate the active catalytic cycle (Scheme 28 ).

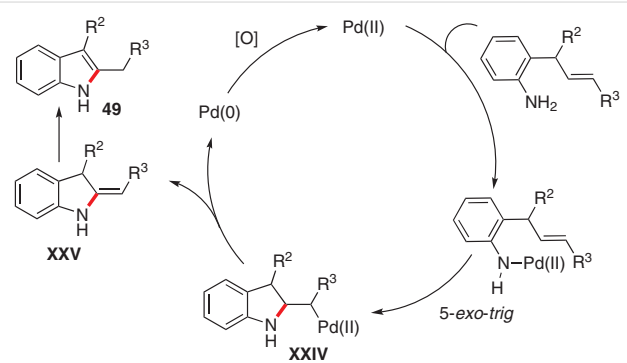

Scheme 28 A plausible catalytic cycle for the synthesis of 3-substituted 2-benzylindoles from 0 -allylanilines

In 2014, Li's group reported the $\mathrm{Rh}(\mathrm{III})$-catalyzed intramolecular annulations of alkynes $\mathbf{5 0}$ via $\mathrm{C}-\mathrm{H}$ activation for the synthesis of 3,4-fused indoles $\mathbf{5 1} .^{24}$ The indoles were synthesized in moderate to good yields with excellent regioselectivity and broad substrate scope. Substrates containing both electron-donating and electron-withdrawing groups at ortho, para and meta positions of the aryl ring of the alkynes were well tolerated. 3,4-Fused indoles with six- to nine-membered rings were generated in relatively low yields (Scheme 29). ${ }^{24}$

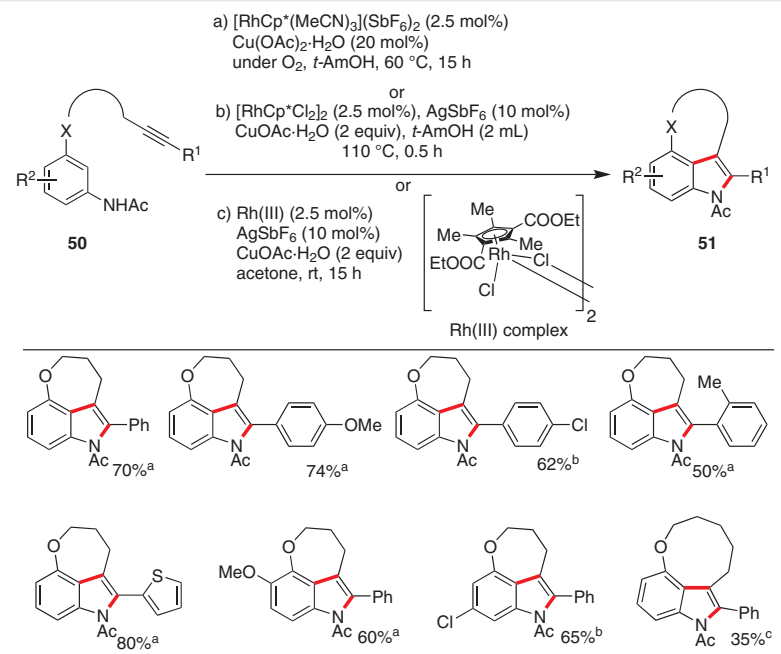

Scheme 29 Rhodium(III)-catalyzed intramolecular synthesis of 3,4fused indoles

The reaction was initiated by ortho $\mathrm{C}-\mathrm{H}$ bond activation of $\mathbf{5 0}$ to form intermediate XXVI. Alkyne insertion to XXVI gives rhodacycle $\mathbf{X X V I I}$, which on reductive elimination provides the desired product $\mathbf{5 1}$ and $\mathrm{Rh}(\mathrm{I})$. Finally, the active catalytic species was regenerated by $\mathrm{Cu}(\mathrm{II})$ (Scheme 30).

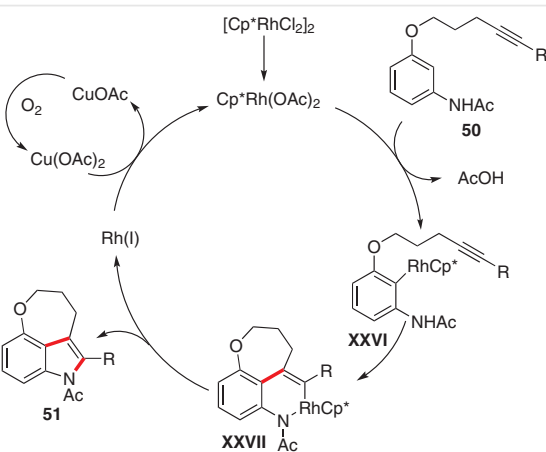

Scheme 30 A plausible catalytic cycle to construct 3,4-fused indoles

In 2016, Dilman et al. described the photocatalyzed conversion of $\mathrm{CF}_{2} \mathrm{I}$-substituted $\mathrm{N}$-arylamines $\mathbf{5 2}$ into the corresponding 3-fluoroindoles $\mathbf{5 3}{ }^{25}$ The starting materials were obtained by nucleophilic iododifluoromethylation of iminium ions. The developed strategy utilized blue LEDs for irradiation of the reaction mixture for 12 hours. A series of 3fluoroindoles was synthesized effectively with excellent yields using the developed photocatalytic methodology (Scheme 31).

Mechanistic studies involved measurements of the redox potentials of the catalyst, the starting material and triphenylphosphine to check the feasibility of the electron-transfer step. The reduction potential studies suggested the initial conversion of photoexcited $\mathrm{Rh}(\mathrm{II})^{*}$ into $\mathrm{Rh}(\mathrm{I})\left[\mathrm{E}_{\mathrm{Rh}(\mathrm{II})^{*} / \mathrm{Rh}(\mathrm{I})}=+0.84 \mathrm{~V}\right]$ by triphenylphosphine $\left[\mathrm{E}_{\mathrm{PPh} 3+/ \mathrm{PPh} 3}=+0.77 \mathrm{~V}\right] . \mathrm{Rh}(\mathrm{I})$ then generates the difluorinated radical XXVIII via a single electron transfer and the catalyst is regenerated. Intramolecular attack of the radical onto the aromatic ring furnished XXIX, oxidation of which by the triphenylphosphine radical cation produced aromatic cation XXX. Elimination of a proton from XXX followed by removal of HF provided the expected indole product (Scheme 32).

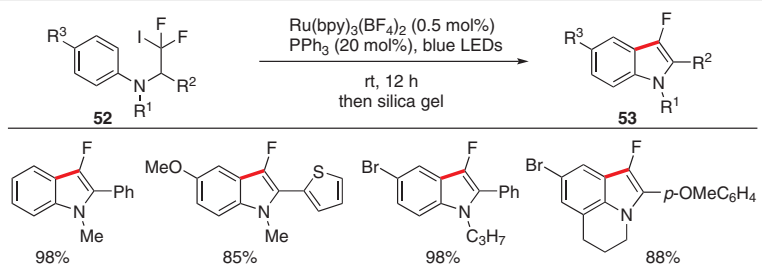

Scheme 31 Photocatalyzed synthesis of 3-fluorinated indoles

In 2016, Miao et al. reported the $\mathrm{ZnEt}_{2}$-mediated antiazacarboxylation of 2-alkynylanilines $\mathbf{5 4}$ with $\mathrm{CO}_{2}$ for the synthesis of 2,3-disubstituted indoles 55 (Scheme 33). ${ }^{26}$ The method represents an easy access to indole moieties as it involves the use of readily available starting materials and various functional groups are tolerated. Trifluoromethyland nitro-substituted reactants provided indoles in good to 


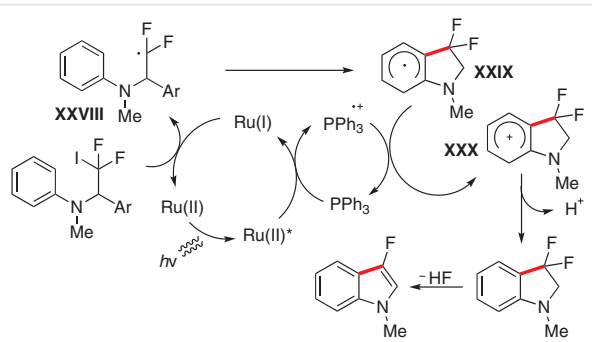

Scheme 32 Mechanistic cycle for the ruthenium-photocatalyzed reaction

excellent yields. The utility of this method involves the synthesis of the drug Lotronex, which is used for the treatment of irritable bowel syndrome.

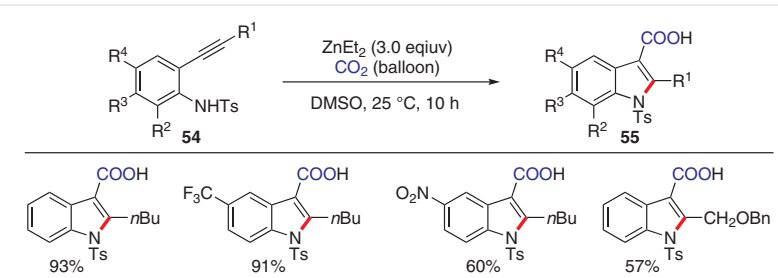

Scheme 33 Diethylzinc-mediated intramolecular cyclization for the synthesis of indoles

The reaction was proposed to proceed through initial activation of the alkyne by diethylzinc making it susceptible to intramolecular nucleophilic attack by nitrogen to generate intermediate XXXI (Scheme 34). The insertion of carbon dioxide into the $\mathrm{C}-\mathrm{Zn}$ bond leads to the formation of XXXII, which on demetalation in the presence of an acid gives the indole.
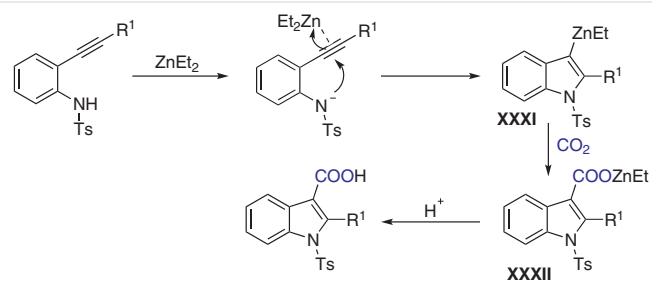

Scheme 34 A plausible reaction mechanism for the synthesis of 2,3disubstituted indoles

\subsection{Metal-Catalyzed Intermolecular 2,3-Disubsti- tuted Indole Synthesis}

Beyond intramolecular indole synthesis, Maurizio Taddei and co-workers reported the Ru-catalyzed H-transfer Fischer indole synthesis of $\mathbf{5 8}$, from primary and secondary alcohols 57 and aryl hydrazines $\mathbf{5 6}$ (Scheme 35). ${ }^{27}$ The use of alcohols in place of aldehydes or ketones makes this sys- tem more advantageous compared to the classical Fischer indole synthesis. ${ }^{27}$

This reaction may proceed through oxidation of the alcohol into a carbonyl compound XXXIII by transfer of a $\mathrm{H}_{2}$ molecule to the crotononitrile. Compound XXXIII is immediately converted into hydrazone XXXIII by reaction with aryl hydrazine $\mathbf{5 6}$ and finally, an acid-catalyzed aromatic $[3+3]$ sigmatropic rearrangement gives the desired indole ring (Scheme 36).

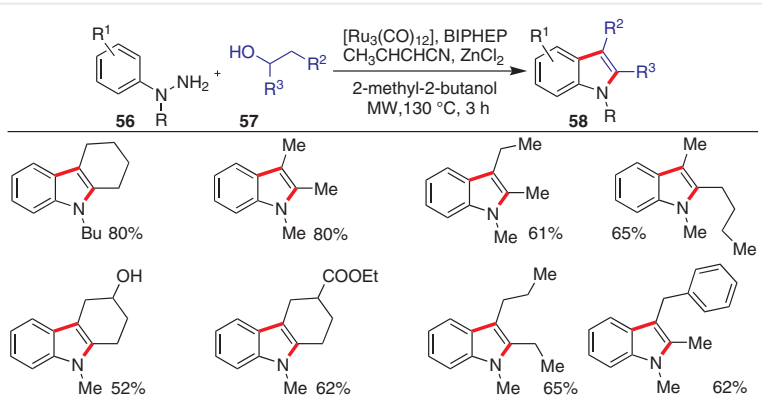

Scheme 35 Ruthenium-catalyzed hydrogen transfer Fischer indole synthesis

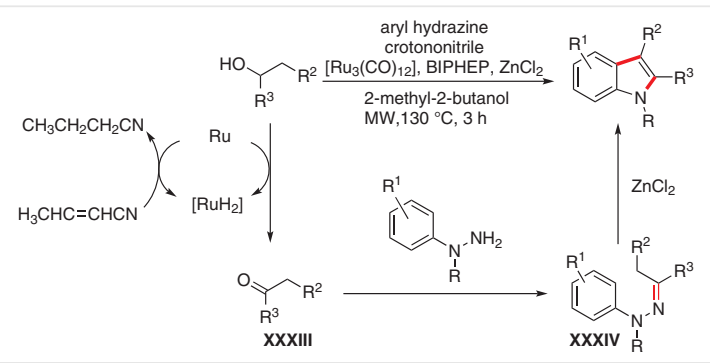

Scheme 36 A plausible catalytic cycle for the synthesis of substituted indoles from aryl hydrazines and alcohols

In 2013, Liang and Zhan reported the copper-catalyzed formation of enehydrazine intermediates $\mathbf{6 1}$ through the coupling of phenyl hydrazines $\mathbf{5 9}$ with vinyl halides $\mathbf{6 0}$, and its synthetic application for the synthesis of indoles $\mathbf{6 2} .^{28}$

This catalytic system tolerates ester, hydroxy and amine functional groups leading to the selective synthesis of isomeric indoles and has been employed for the interrupted indolization to synthesize the pyrrolidinoindoline $\mathbf{6 2}$ (Scheme 37). This catalytic system opens a new way for the asymmetric synthesis of indoles. ${ }^{29}$

Zhu and co-workers reported a $\mathrm{Rh}(\mathrm{III})$-catalyzed, $\mathrm{C}-\mathrm{H}$ activation based intermolecular redox neutral strategy for the synthesis of indoles $\mathbf{6 5}$ by cyclization of $N$-nitrosoanilines 63 with alkynes 64 using the $\mathrm{N}-\mathrm{N}$ bond as an internal oxidant. This catalytic procedure showed good functional group tolerance and the compatibility of seemingly dichotomous acidic and basic conditions makes it a versatile method (Scheme 38). ${ }^{30}$ 


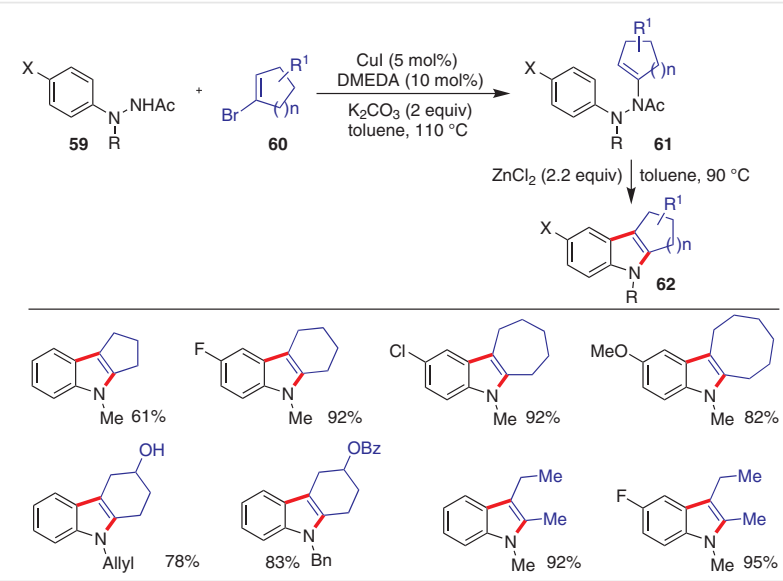

Scheme 37 Copper-catalyzed Fischer indole synthesis through formation of enehydrazine intermediates from phenyl hydrazines and vinyl halides

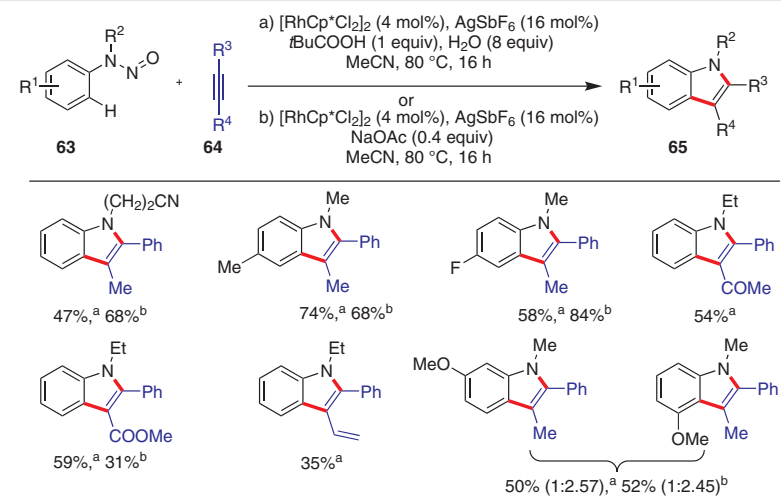

Scheme $38 \mathrm{Rh}$ (III)-catalyzed synthesis of indoles from $\mathrm{N}$-nitrosoanilines and alkynes using the $\mathrm{N}-\mathrm{N}$ bond as an internal oxidant

A detailed mechanistic study proved that the generation of $\left[\mathrm{RhCp}^{*}\right]^{2+}$ leads to reversible coordination of $t \mathrm{BuCOO}^{-}$and $\mathrm{N}$-nitrosoaniline derivative to give $\mathbf{X X X X V}$, and the turnoverlimiting $\mathrm{C}-\mathrm{H}$ activation then forms rhodium intermediate XXXVI via a $\mathrm{BuCOO}^{-}$-assisted CMD (concerted metallation deprotonation) pathway. Interaction of the alkyne with XXXVI followed by migratory insertion leads to the formation of intermediate XXXVII. Concerted $\mathrm{N}-\mathrm{N}$ bond cleavage and $\mathrm{C}-\mathrm{N}$ bond formation leads to formation of the final product with the abstraction of $\mathrm{NO}^{+}$by $\mathrm{H}^{+}$and regeneration of the active $\left[\mathrm{RhCp}^{*}\right]^{2+}$ species (Scheme 39 ). ${ }^{30}$

In 2013, Senanayake and co-workers disclosed the onepot synthesis of indoles $\mathbf{6 9}$ by reacting 2-bromoanilides $\mathbf{6 6}$, terminal alkynes $\mathbf{6 7}$, and aryl halides $\mathbf{6 8}$ via a palladiumcatalyzed reaction sequence involving Sonogashira coupling, aminopalladation and reductive elimination (Scheme 40). ${ }^{31}$ All the reactions were carried under normal conditions without the use of $n \mathrm{Bu}_{4} \mathrm{NBr}$ and good to excellent yields were achieved.

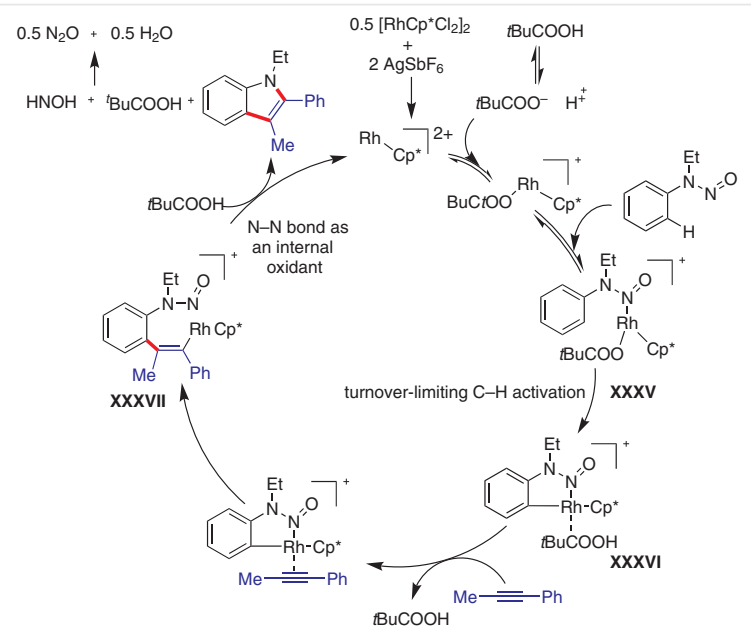

Scheme 39 Proposed mechanism for the intermolecular redox neutral synthesis of indoles

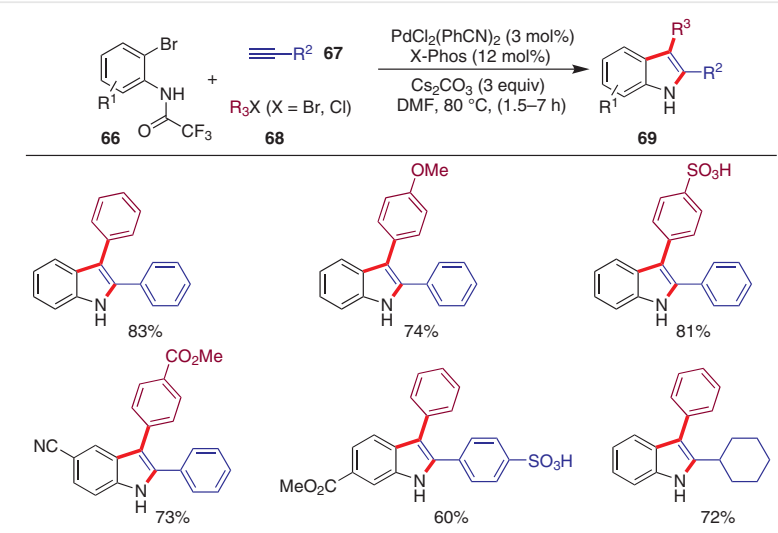

Scheme 40 Synthesis of 2,3-disubstituted indoles from 2-bromo- or 2-chloroanilides, terminal alkynes and aryl halides

In 2013, Ding et al. reported the Ru complex and $p$-TSA catalyzed synthesis of indole derivatives $\mathbf{7 2}$ from anilines 70 and vicinal diols 71. Electron-donating substituents on the aryl ring of the aniline gave the products in higher

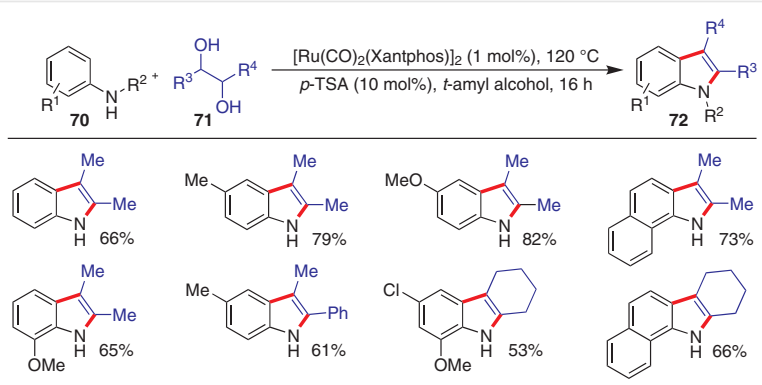

Scheme 41 Indole synthesis from anilines and vicinal diols by cooperative catalysis of a ruthenium complex and an acid 
yields, while strong electron-withdrawing groups (i.e., $\mathrm{NO}_{2}$ or $\mathrm{CF}_{3}$ ) failed to give the expected products. An ortho-substituted aniline gave a lower yield because of steric hindrance (Scheme 41). ${ }^{32}$

A year later, Driver and co-workers reported a Suzuki cross-coupling reaction for the regioselective synthesis of 2,3-fused indole heterocycles 76 from 2-azidoarylboronic esters 73 and vinyl triflates $\mathbf{7 4} .^{33}$ The 5-substituted aryl azides smoothly gave the indole products; these products cannot be accessed as single regioisomers using the Fisher indole reaction. The conversion of androsterone into an indole proved that this method is applicable for complex molecules, albeit a reduced yield was obtained (Scheme 42). ${ }^{33}$

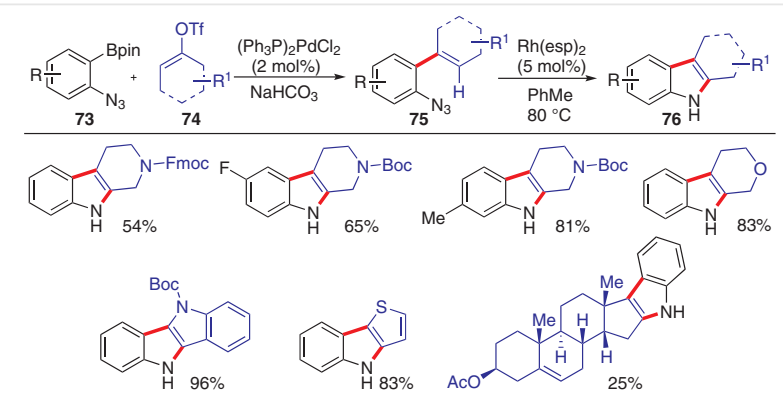

Scheme 42 The synthesis of 2,3-fused indole heterocycles

In the same year (2104), Cho and co-workers reported the synthesis of ene-hydrazides $\mathbf{7 9}$ from bis-Boc-hydrazide $\mathbf{7 7}$ and enol triflates $\mathbf{7 8}$, and their subsequent enolization reaction to give the regioselective Fischer indole products 80. The catalytic system showed broad substrate scope and enabled the synthesis of indole natural products with excellent regioselectivities (Scheme 43). ${ }^{34}$

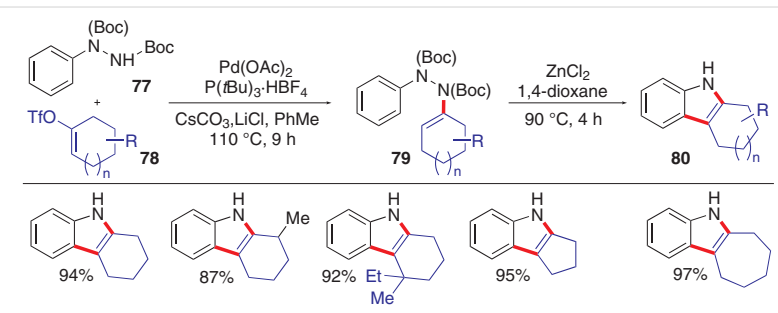

Scheme 43 Regioselective Fischer indole synthesis from ene-hydrazides

In 2014, Wu's group reported the synthesis of $\mathrm{N}$-(2-pyridyl)indoles 83 from internal alkynes 82 and $N$-phenylpyridin-2-amines $\mathbf{8 1}$ catalyzed by palladium@cerium(IV) oxide. This method affords better yields compared to other heterogeneous catalytic methods and demonstrates good functional group tolerance; however, the nitro functional group was not tolerated (Scheme 44). ${ }^{35}$

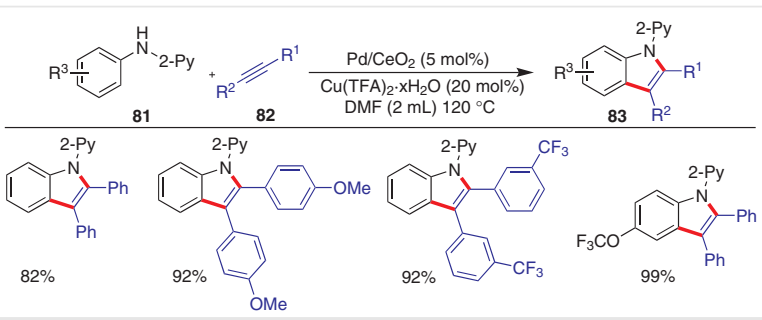

Scheme 44 Oxidative synthesis of $\mathrm{N}$-(2-pyridyl)indoles

The regio- and enantioselective synthesis of $N$-allyl indoles $\mathbf{8 6}$ and $\mathbf{8 7}$ was reported by You's group in $2014 .^{36}$ This reaction proceeds through an Ir-catalyzed asymmetric allylic amination with 2-alkynylanilines 84 and subsequent Au-catalyzed cyclization. The catalytic system proved was applicable to a broad substrate scope, affording high yields and good enantiomeric excess. The reaction was also compatible with a one-pot procedure and cascade reaction (Scheme 45). ${ }^{36}$

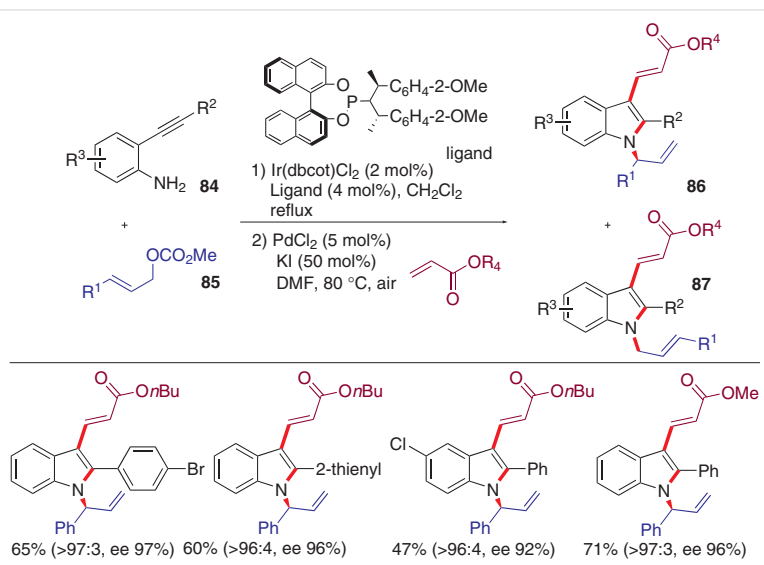

Scheme 45 Ir-catalyzed allylic amination and subsequent Au-catalyzed cyclization

The Yu group reported, in 2015, the Pd(II)-catalyzed synthesis of functionalized indoles $\mathbf{9 0}$ from simple N-substituted pyrroles $\mathbf{8 8}$ and 3-chloropropiophenones $\mathbf{8 9}$ and

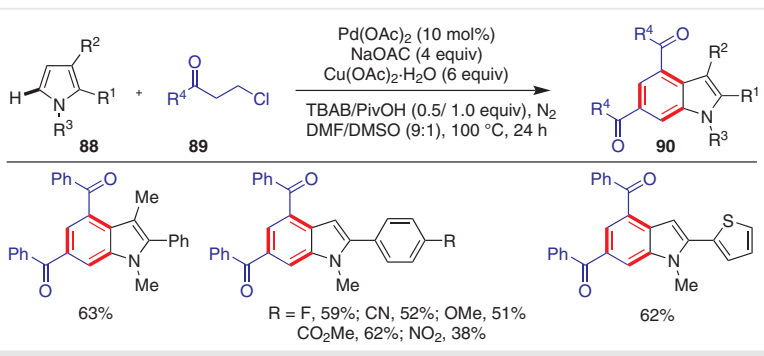

Scheme $46 \mathrm{Pd}(\mathrm{II})$-catalyzed synthesis of functionalized indoles from pyrroles and enones 
their analogues. This reaction proceeds through the construction of a benzene ring onto a pyrrole backbone using enones 89 (Scheme 46). ${ }^{12}$

The proposed catalytic cycle started with palladation at the $\mathrm{C}-5$ position of pyrrole $\mathbf{8 8}$ giving intermediate $\mathbf{X X X V I I I}$ with simultaneous removal of acetic acid. Intermediate $\mathbf{X X X V I I I}$ then reacts with the enone $\mathbf{X X X I X}$, generated from 3-chloropropiophenone $\mathbf{8 9}$, to form palladium intermediate XL. Reductive elimination leads to the formation of pyrrole derivative $\mathbf{X L I}$, which undergoes a Diels-Alder cycloaddition with another molecule of the enone to form tetrahydroindole XLII. Finally, the tetrahydroindole is oxidized to indole $\mathbf{9 0}$ and catalytic system is regenerated by $\mathrm{Cu}(\mathrm{II})$ oxidant or air (Scheme 47).

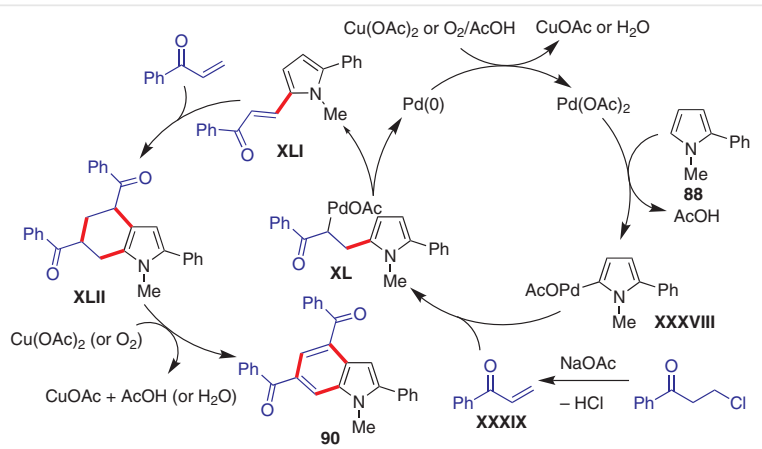

Scheme 47 Proposed mechanism for the synthesis of functionalized indoles from pyrroles and 3-chloropropiophenones

In 2015, Dong and co-workers reported the Ru(II)-catalyzed oxidative coupling via $\mathrm{C}-\mathrm{H}$ activation of $\mathrm{NH}$ protic amides $\mathbf{9 1}$ with alkynes $\mathbf{9 2}$ for the synthesis of $\mathrm{N}$-acylindole derivatives $\mathbf{9 3}$. This catalytic method shows good functional group tolerance and affords moderate yields of the products (Scheme 48). ${ }^{37}$

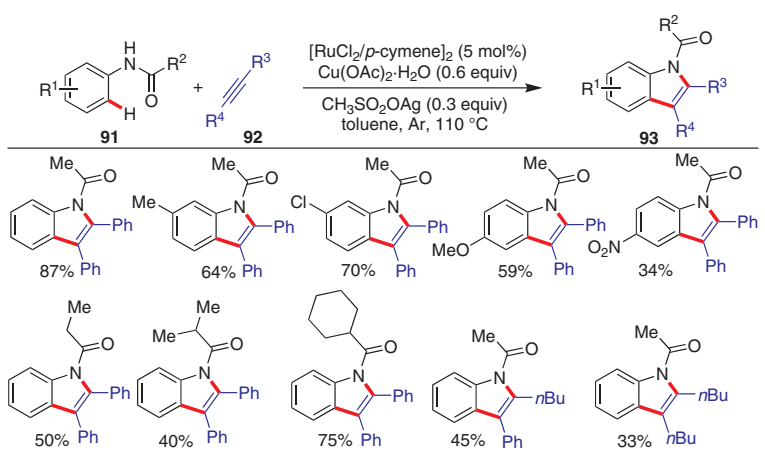

Scheme 48 Synthesis of indoles via ruthenium(II)-catalyzed C-H activation and annulations

A plausible mechanism was proposed in which the insertion of $\mathrm{Ru}$ (II) metal activates the ortho $\mathrm{C}-\mathrm{H}$ bond of amide $\mathbf{9 1}$ to form the six-membered ruthenacycle XLII. Alkyne interaction with XLIII followed by migratory insertion leads to the formation of another ruthenacycle (XLIV). Finally, reductive elimination provides the product 93 (Scheme 49). ${ }^{37}$

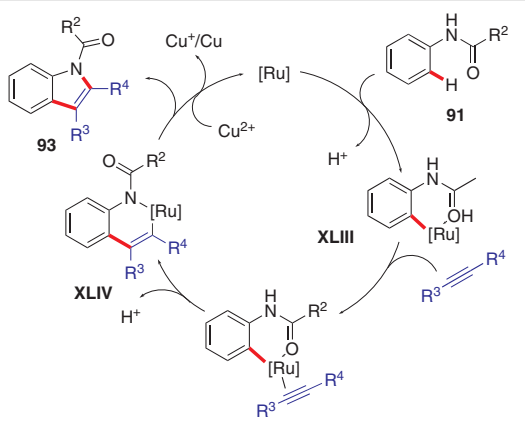

Scheme 49 Proposed catalytic cycle for the synthesis of $\mathrm{N}$-acylindoles from $\mathrm{NH}$ protic amides and alkynes

In 2015, Hwang's group reported the visible-light-mediated $\mathbf{C u C l}$-catalyzed regioselective synthesis of indoles $\mathbf{9 7}$ via coupling of arylamines 94, terminal alkynes 95 and quinines 96 at room temperature (Scheme 50). This photoinduced method showed broad substrate scope with good to excellent selectivities. However, the use of meta-substituted anilines resulted in the formation of a mixture of regioisomers. $^{38}$

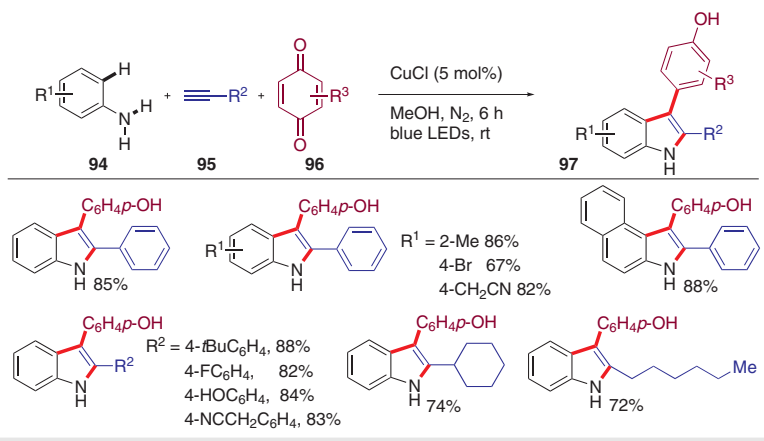

Scheme 50 Photoinduced copper-catalyzed synthesis of indoles from arylamines, terminal alkynes and quinines

This reaction was proposed to commence by photoirradiation of in situ generated XLV by blue LEDs. This produces the photoexcited triplet state XLVI ( $\tau=15.95 \mu \mathrm{s})$ by ligandto-metal charge transfer (LMCT). ${ }^{39}$ This is followed by intersystem crossing of the singlet excited state of copper(I) phenylacetylide to the triplet excited state. ${ }^{40}$ Next, a SET process with benzoquinone gives the copper(II) phenylacetylide XLVII and benzoquinone radical XIVIII, which has the tendency to attack XLVII to regenerate the copper(I) catalyst and form copper(I)-coordinated alkyne complex XLIX. The electrophilicity of the triple bond in the disubstituted alkyne moiety must be enhanced through coordination with $\mathrm{CuCl}^{41}$ facilitating nucleophilic attack by aniline to provide complex $\mathbf{L}$, thus leading to the formation of com- 
plex LI. Friedel-Crafts-type cyclization then generates the intermediate $\mathbf{L I I}^{42}$ and finally, a rearomatization process provides the indole product (Scheme 51 ).

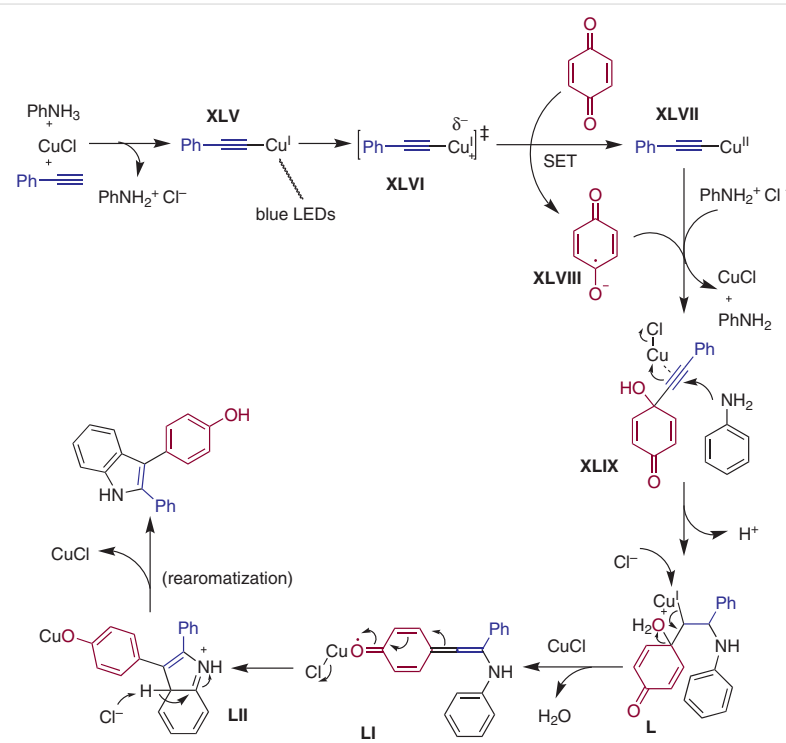

Scheme 51 Proposed mechanism for the photoinduced synthesis of indoles

Lu's group reported the Rh(III)-catalyzed synthesis of indoles 100 by annulation of arylnitrones 98 and alkynes 99 without using any external oxidant. Symmetric diarylacetylenes bearing various substituents at the para and meta positions gave the best results. ${ }^{43}$ While ortho-methyl-substituted diarylacetylene gave a low yield, an unsymmetrical diarylacetylene afforded a mixture of two regioisomers. para-Cyano-substituted $\mathrm{N}$-phenyl-C-mesitylnitrone appeared to be a less effective substrate, affording the desired product in a low yield with a higher catalyst loading at $100{ }^{\circ} \mathrm{C}$ (Scheme 52). ${ }^{43}$

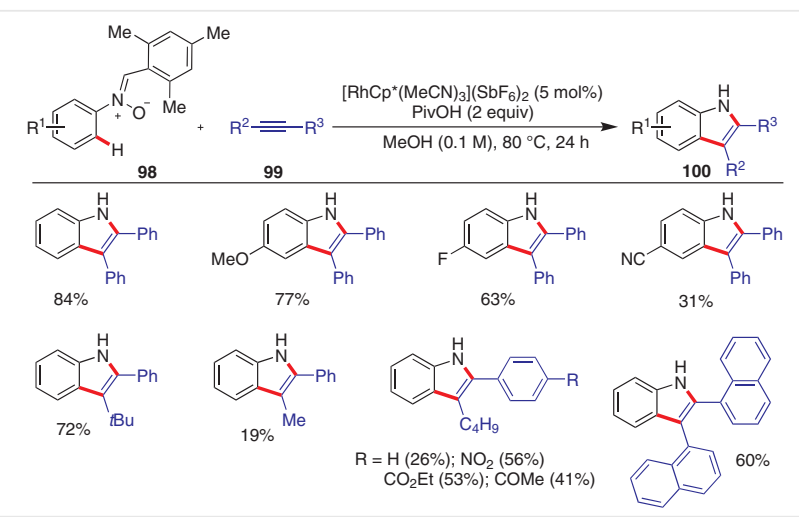

Scheme 52 Rh(III)-catalyzed synthesis of indole derivatives from arylnitrones and alkynes
The catalytic cycle was initiated with the formation of rhodacycle LIII followed by insertion of the alkyne to give the seven-membered intermediate LIV. Reductive elimination leads to the formation of intermediate $\mathbf{L V}$. This resulting $\mathrm{Rh}(\mathrm{I})$ intermediate could be oxidized by the $\mathrm{N}-\mathrm{O}$ bond via oxidative addition to provide enolate LVI, which upon protonolysis provides intermediate LVII and regenerates $\mathrm{Rh}$ (III) to complete the cycle. Enolate intermediate LVII is in equilibrium with keto intermediate LVIII, which gives the indole by imine hydrolysis and intramolecular cyclization (Scheme 53).

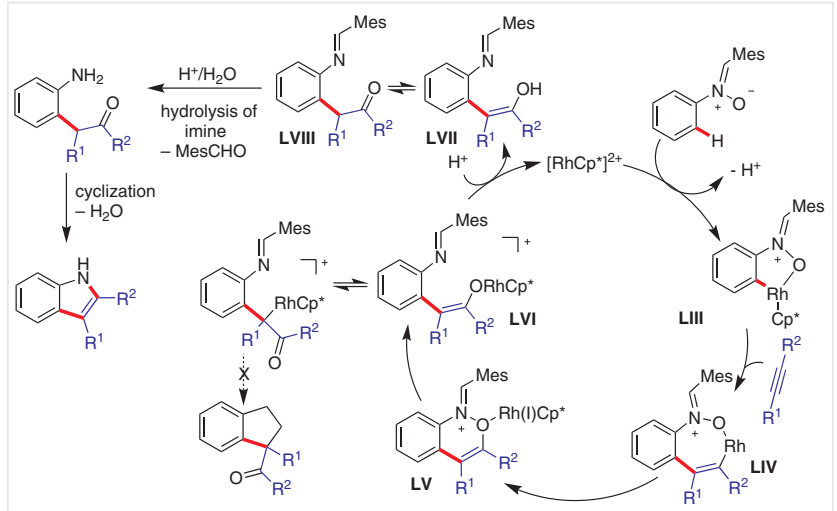

Scheme 53 Proposed catalytic cycle for indole synthesis from arylnitrones and alkynes

In 2015, Wan and co-workers reported the synthesis of unsymmetrical 2,3-diaryl-substituted $\mathrm{N}$-unprotected indoles 103 via rhodium-catalyzed $\mathrm{C}-\mathrm{H}$ annulations of nitrones 101 with symmetrical alkynes 102 (Scheme 54). ${ }^{44}$ The catalytic system showed tolerance of various functional groups on the aryl rings of the nitrones and the symmetrical alkynes for the regioselective preparation of the 2,3disubstituted indoles 103.

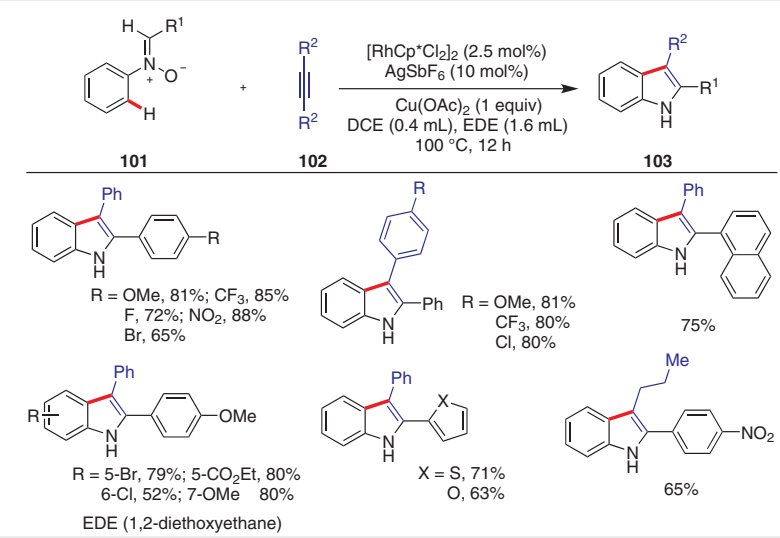

Scheme 54 Rhodium-catalyzed synthesis of 2,3-diaryl-substituted indoles from nitrones and alkynes 


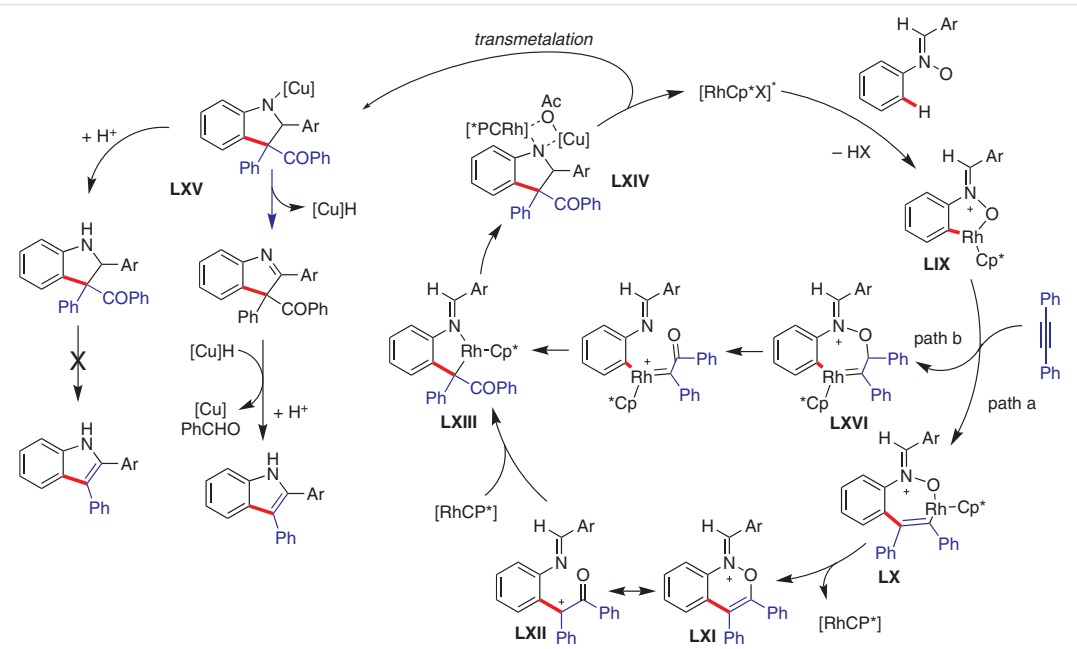

Scheme 55 A plausible catalytic cycle for the synthesis of unsymmetrical 2,3-disubstituted indoles

The catalytic cycle of this reaction also involves the formation of a rhodacyclic intermediate LIX, which undergoes insertion with the alkyne to give the seven-membered intermediate $\mathbf{L X}$ (Scheme 55, path a). Reductive elimination then provides the intermediate LXI. Intramolecular oxygen atom transfer and subsequent oxidative addition of LXII and electrophilic cyclization generates intermediate LXIII. Intermediate $\mathbf{L X V}$ is formed by transmetalation and subsequent $\beta$-hydride elimination, ${ }^{45}$ finally leading to the formation of product 103 by elimination of $\mathrm{PhCHO} .{ }^{46}$ Alternatively, the reaction can proceed through LIX and intermediate LXVI (Scheme 55, path b).

Wang and Huang, in 2015, developed a general protocol for the synthesis of $\mathrm{N}$-alkylindoles $\mathbf{1 0 5}$ using a traceless nitroso directing group via redox neutral $\mathrm{C}-\mathrm{H}$ activation (Scheme 56). ${ }^{47}$ This rhodium-based catalytic system provided $\mathrm{N}$-alkylindoles regioselectively, with a broad scope of substituents, in good to excellent yields and without the use of any oxidant or other additive.

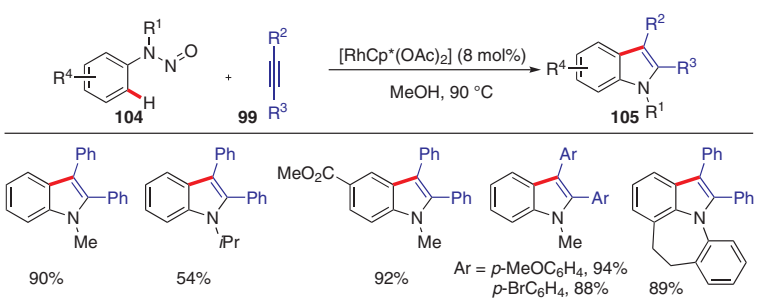

Scheme 56 Redox neutral C-H activation for the regioselective synthesis of $\mathrm{N}$-alkylindoles

Though the full catalytic cycle of the reaction remains elusive, the $\mathrm{C}-\mathrm{H}$ activation step may proceed via a concerted metalation-deprotonation (CMD) mechanism.
In 2010, the Knochel group reported a microwave-assisted Fischer indole synthesis for the preparation of polyfunctional indoles $\mathbf{1 0 9}$ from aryldiazonium tetrafluoroborates 108 and functionalized alkylzinc halides 107, which were generated from substituted bromobutanes 106 (Scheme 57). ${ }^{48}$ The catalytic system showed a broad substrate scope with excellent regioselectivity, and with many functional groups such as nitro, ester, keto, cyano and iodo being tolerated. This catalytic method was successfully used for the synthesis of indole-containing drug molecules.

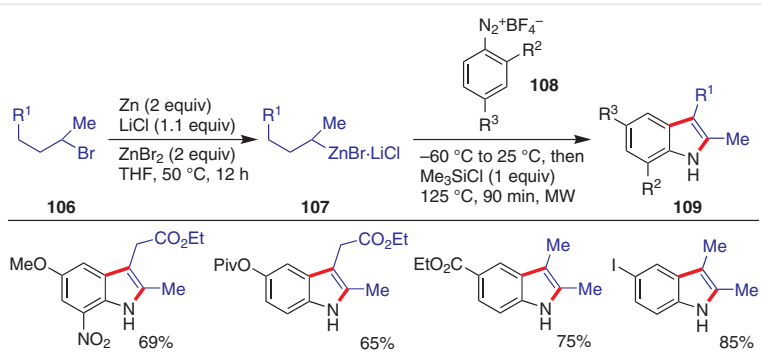

Scheme $\mathbf{5 7}$ Preparation of polyfunctional indoles by the addition of alkylzinc reagents to aryldiazonium tetrafluoroborates

Hui Jiang and co-workers reported the rhodium(III)-catalyzed regioselective synthesis of indole-3-carboxylic acid esters 112 using a pyrimidyl directing group. ${ }^{49} \mathrm{~N}$-Substituted anilines $\mathbf{1 1 0}$ and diazo compounds $\mathbf{1 1 1}$ were used as the starting materials and the reactions proceeded via aromatic $\mathrm{C}-\mathrm{H}$ bond activation followed by $\mathrm{C}-\mathrm{N}$ bond formation to give 2,3-difunctionalized indoles (Scheme 58). The presence of the pyrimidyl directing group was essential for the synthesis of the desired indoles under the specified conditions, and it can be reutilized for further functionalization of the synthesized indoles, or can be easily removed to provide different free $\mathrm{N}-\mathrm{H}$ indoles. The limitations of preactivated substrates, the requirement for excess oxidant and 
the substrate scope associated with the previous reports of Glorius, ${ }^{50}$ Jiao $^{51}$ and Cacchi ${ }^{21}$ for the synthesis of indole-3carboxylic acid esters were overcome by using this method. Various alkyl, halogen and ester substituents on the phenyl ring were well tolerated under the reported conditions. Substituents with strong-electron withdrawing effects such as $\mathrm{CF}_{3}$ and $\mathrm{NO}_{2}$ and electron-donating methoxy substituents afforded the expected products, exclusively. The desired indole was obtained with a morpholinyl substituent at the para position of the phenyl ring. Also, the reaction was successful on gram scale.

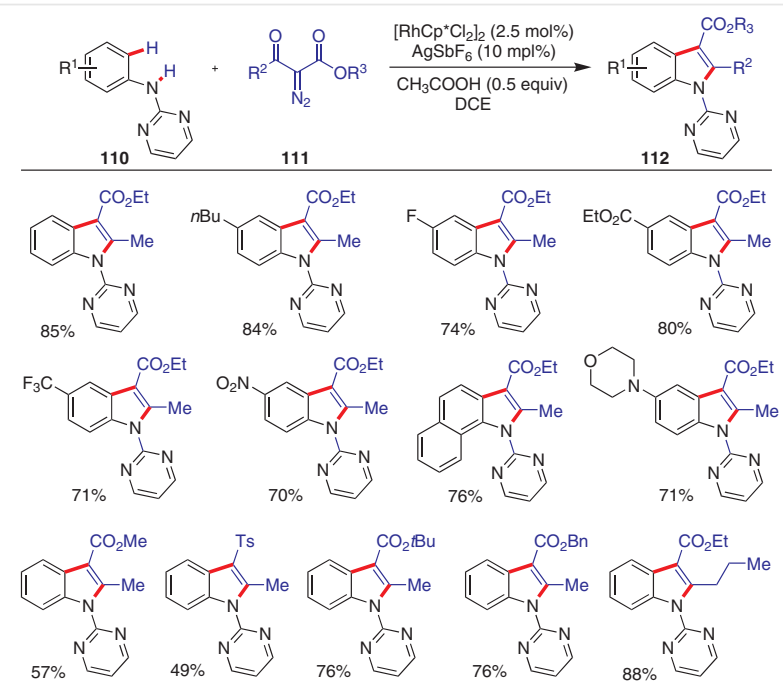

Scheme 58 Regioselective synthesis of indole-3-carboxylic acid esters

In 2016, Li's group described the synthesis of 2,3-disubstituted indoles 115 via C-H activation/annulation of imidamides 113 with diaza-ketoesters 114 using a Rh(III) catalyst (Scheme 59). ${ }^{52}$ This redox-neutral strategy proceeded under mild conditions with a variety of substrates.

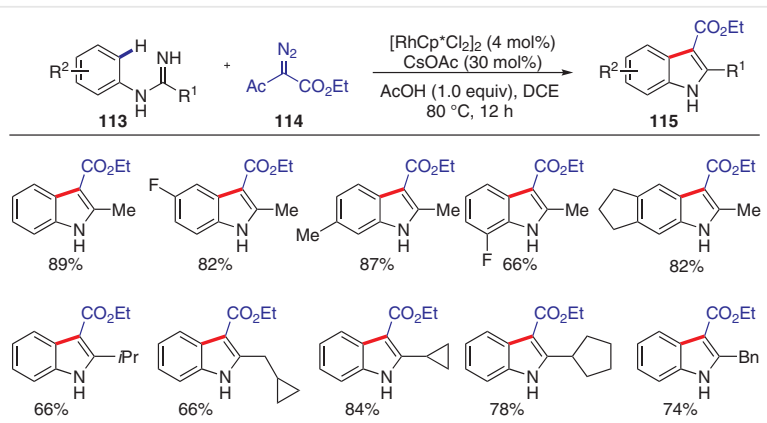

Scheme 59 Rhodium-catalyzed synthesis of 2,3-disubstituted indoles

The mechanistic studies of the reaction revealed the kinetic isotope effect (KIE) value to be 3.3, which indicates C$\mathrm{H}$ bond cleavage may be involved in the rate-determining step. The proposed mechanism of the reaction includes the initial generation of an active catalyst through anion exchange. Insertion of the active catalyst into the ortho $\mathrm{C}-\mathrm{H}$ bond followed by cyclization gives the six-membered rhodacycle LXVII. Elimination of nitrogen with subsequent insertion of the diazo substrate generates LXVIII and migratory insertion of the $\mathrm{Rh}-\mathrm{C}$ bond into the $\mathrm{C}=\mathrm{N}$ bond provides LXIX. Protonolysis of LXIX generates LXX and the active catalyst. The elimination of acetamide from $\mathbf{L X X}$ gives the final product (Scheme 60).

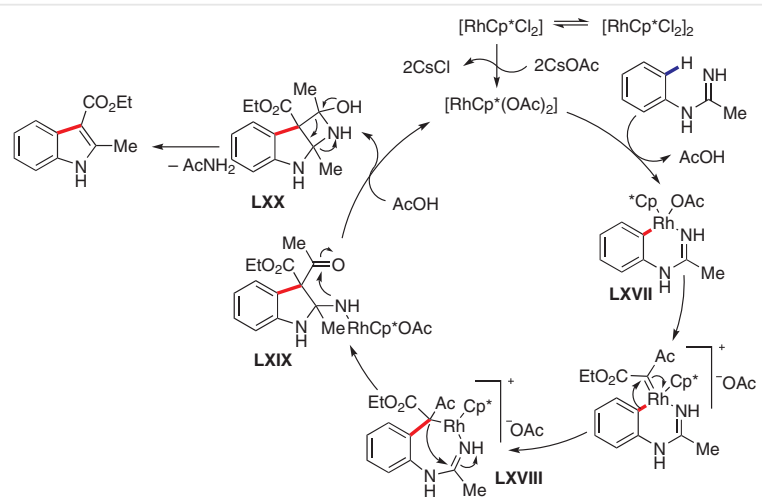

Scheme 60 Suggested catalytic cycle for the $\mathrm{C}-\mathrm{H}$ activation/annulation of imidamides with diaza-ketoesters

Recently, in 2016, Wu et al. developed an oxidant-free intramolecular $\mathrm{C}-\mathrm{C}$ bond-formation strategy for the regioselective synthesis of indoles $\mathbf{1 1 7}$ using an iridium(II) photosensitizer and a cobaloxime catalyst under visible light irradiation (LEDs, $450 \mathrm{~nm}$ ). This procedure successfully converted $\mathrm{N}$-arylenamines $\mathbf{1 1 6}$ into indoles in good to excellent yields, while producing $\mathrm{H}_{2}$ as the only side product (Scheme $61) .^{53}$ The reported method overcomes the limitations of Glorius and co-worker's ${ }^{50}$ procedure using a stoichiometric amount of oxidant, which can lead to the formation of side products. Under the optimized reaction conditions, various electron-withdrawing as well as electron-donating substituents were well tolerated, affording the corresponding indoles in high yields. When meta-substituted enamines were

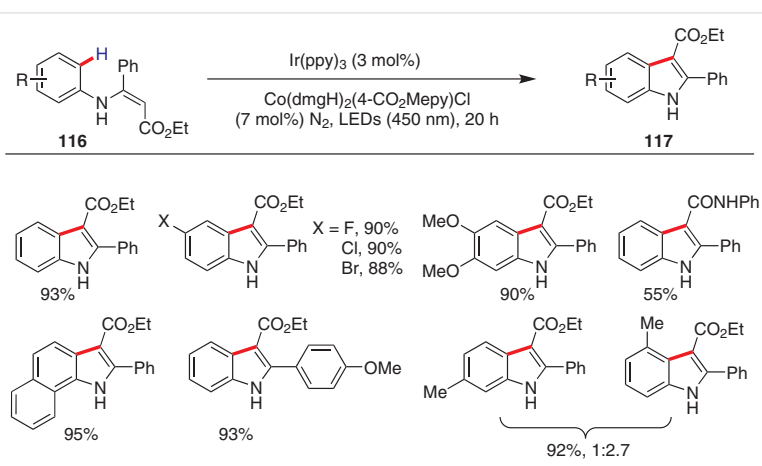

Scheme 61 Photocatalyzed regioselective synthesis of indoles 


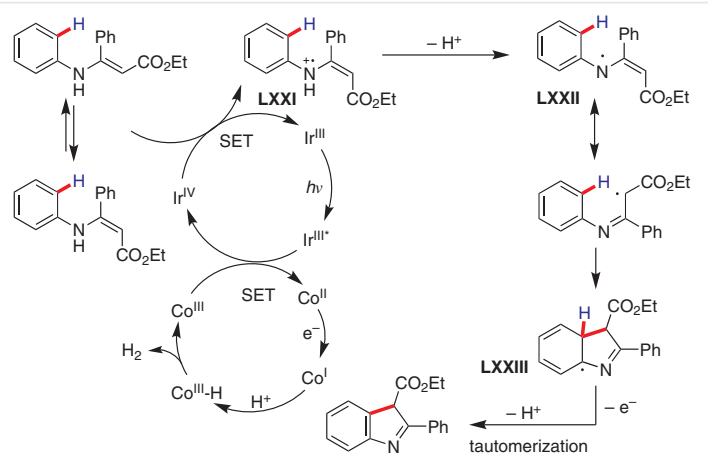

Scheme 62 A plausible mechanism for the photocatalytic synthesis of indole derivatives

used as the starting materials, more than one product could be obtained. The desired indole product could also be obtained on gram scale in $82 \%$ yield.

A plausible mechanism for the reaction involves initial photoirradiation of the $\operatorname{Ir}(\mathrm{ppy})_{3}$ photosensitizer to produce $\operatorname{Ir}(\mathrm{ppy})_{3}{ }^{*}$, which transfers an electron to the cobaloxime complex, thus forming $\operatorname{Ir}(\mathrm{IV})$ and $\operatorname{Co}(\mathrm{II})$. The $\operatorname{Ir}(\mathrm{IV})$ so formed abstracts an electron from $\mathbf{1 1 6}$ to produce $\mathbf{L X X I}$ and regenerate the photosensitizer $\operatorname{Ir}(\mathrm{ppy})_{3}$. Intermediate $\mathbf{L X X I}$ loses a proton to give LXXII that undergoes intramolecular radical cyclization to produce LXXIII. Finally, oxidation and deprotonation followed by tautomerization of LXXIII afforded the desired indole product (Scheme 62).

In 2014, Zhang et al. developed a regioselective synthesis of polysubstituted indoles $\mathbf{1 2 0}$ via an Ru-catalyzed redox-neutral $\mathrm{C}-\mathrm{H}$ activation reaction involving $\mathrm{N}-\mathrm{N}$ bond cleavage..$^{54}$ The $\mathrm{C}-\mathrm{H}$ annulation reaction of alkynes $\mathbf{1 1 9}$ was carried out using pyrazolidin-3-one $\mathbf{1 1 8}$ as the internal oxidant as well as the directing group (Scheme 63). The use of ruthenium metal avoided homocoupling of the terminal alkynes, which was a major side reaction when using $\mathrm{Rh}(\mathrm{III})$. Also, the oxidative potential of the $\mathrm{N}-\mathrm{N}$ bond of the aliphatic hydrazine was not enough to regenerate the $\mathrm{Ru}(\mathrm{II})$ catalyst. So, the authors used cyclic hydrazides with increased ring strain to activate the N-N bond. The designed protocol was effective for a broad range of functional groups on the arene moiety: electron-withdrawing as well as electron-donating substituents were well tolerated. Symmetrical, unsymmetrical and 1-substituted alkynes gave single regioisomers, exclusively. The utility of the developed method was demonstrated by the synthesis of a P2 inhibitor, ${ }^{55}$ a SIRT1 activator ${ }^{56}$ and an NS5B inhibitor. ${ }^{57}$

A plausible $\mathrm{Ru}(\mathrm{II})-\mathrm{Ru}(\mathrm{IV})-\mathrm{Ru}(\mathrm{II})$ catalytic mechanism for the reaction was proposed on the basis of redox-neutral $\mathrm{Rh}$ catalysis reported in the literature ${ }^{58} \mathrm{Ru}(\mathrm{II})$ amido complex LXXIV is obtained by initial insertion of the active $\mathrm{Ru}(\mathrm{II})$ acetate into the $\mathrm{N}-\mathrm{H}$ bond of pyrazolidin-3-one, which undergoes metalation-deprotonation to give LXXV. Subsequent alkyne insertion followed by oxidation to $\mathrm{Ru}(\mathrm{IV})$ by the $\mathrm{N}-\mathrm{N}$

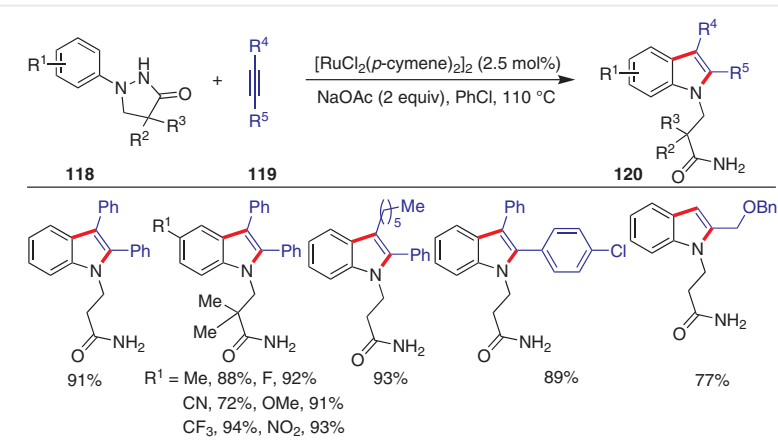

Scheme 63 Ruthenium-catalyzed redox-neutral C-H activation, regioselective synthesis of $\mathrm{N}$-substituted indoles

bond gives LXXVI, which upon reductive elimination gives the final product and regenerates the active $\mathrm{Ru}(\mathrm{II})$ catalyst (Scheme 64).

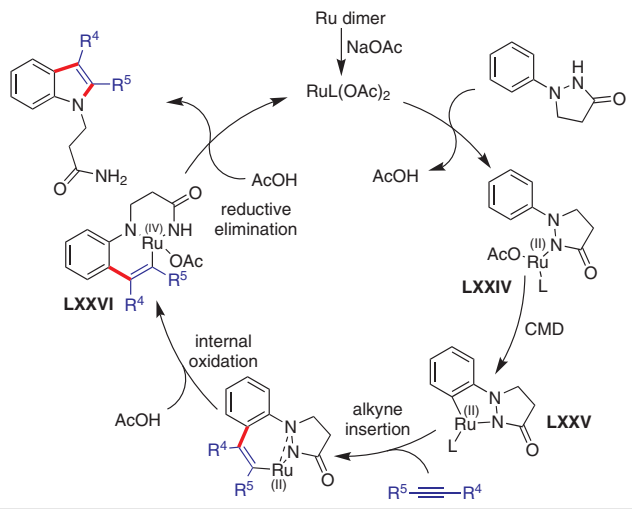

Scheme 64 Proposed catalytic cycle for the synthesis of polysubstituted indole derivatives

In 2016, Zhou et al. developed a versatile, traceless, $\mathrm{Rh}(\mathrm{III})$-catalyzed annulation of arylhydrazines $\mathbf{1 2 1}$ and alkynes $\mathbf{9 9}$ for the synthesis of indoles $\mathbf{1 2 2}$, with a very low catalyst loading $(0.1 \mathrm{~mol} \%)$ on gram-scale reactions (Scheme 65). ${ }^{59}$ The $\mathrm{N}$-amino-directed $\mathrm{C}-\mathrm{H}$ alkenylation generated indoles in a step- and atom-economic manner at

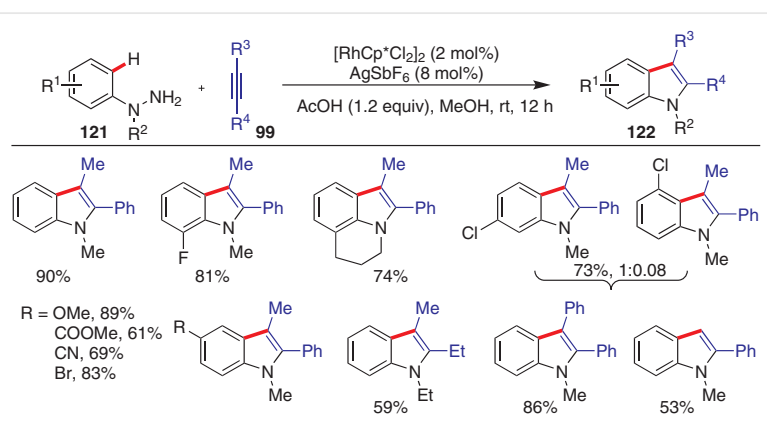

Scheme 65 Traceless synthesis of indoles at room temperature 
room temperature and showed tolerance toward a broad range of functional groups on the arylhydrazines and alkynes. The room-temperature conditions for the traceless indole synthesis are unexcelled via $\mathrm{C}-\mathrm{H}$ activation strategy.

In 2014, Liu's group reported the Rh-catalyzed synthesis of 1-aminoindole derivatives 124 via oxidative annulation of hydrazines 123 with alkynes 99 (Scheme 66). ${ }^{60}$ The authors described the use of 1,3-dinitrobenzene as an oxidant in transition-metal-catalyzed $\mathrm{C}-\mathrm{H}$ activation for the first time. ${ }^{58 \mathrm{a}}$

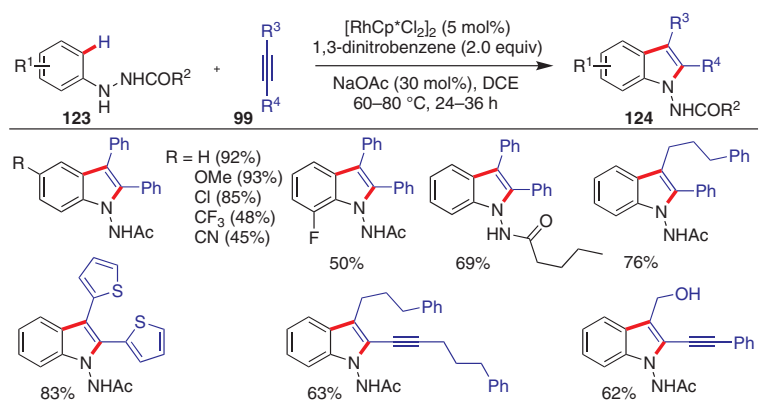

Scheme 66 Oxidative annulations of hydrazines and alkynes to give indoles

The course of the reaction includes formation of rhodacycle LXXVII by insertion of the active metal catalyst into the hydrazine. Alkyne coordination and insertion gives a more stable six-membered intermediate LXXVIII, which undergoes internal oxidation to release the indole in the presence of $\mathrm{AcOH}$. The active catalyst is regenerated by the external oxidant, 1,3-dinitrobenzene (Scheme 67).

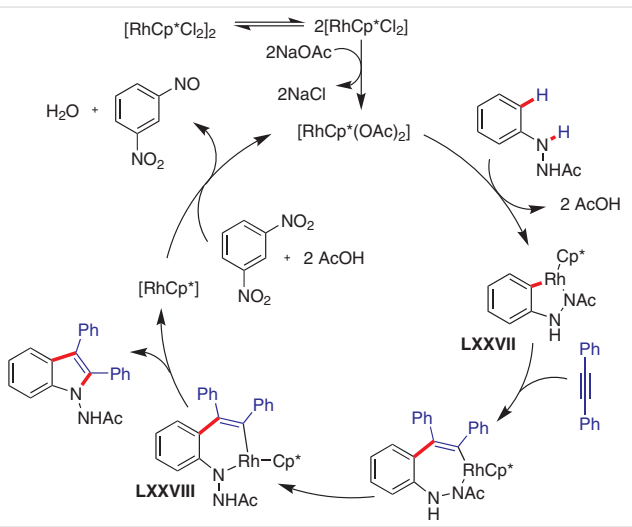

Scheme 67 A plausible reaction mechanism

In 2016, Zhang and co-workers developed a new strategy for the synthesis of indoles 126 via Co(III)-catalyzed oxidative annulations of $\mathrm{N}$-arylureas 125 and alkynes 99 possessing a broad range of synthetically useful substituents (Scheme 68). ${ }^{61}$ However, the strategy is limited to the use of less electrophilic ureas other than acetamide as the directing groups, and gave the products in good to excellent yields.

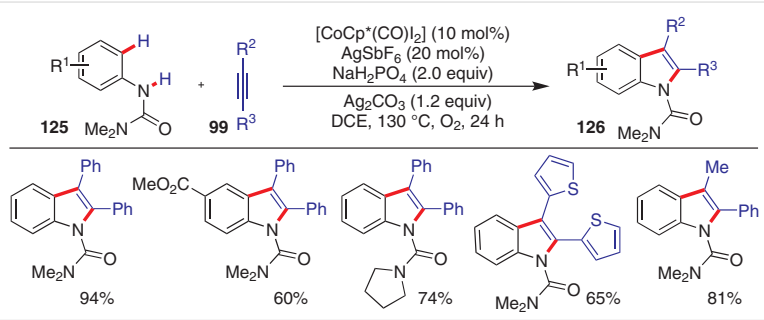

Scheme $68 \mathrm{Co}$ (III)-catalyzed oxidative coupling of $\mathrm{N}$-arylureas and internal alkynes

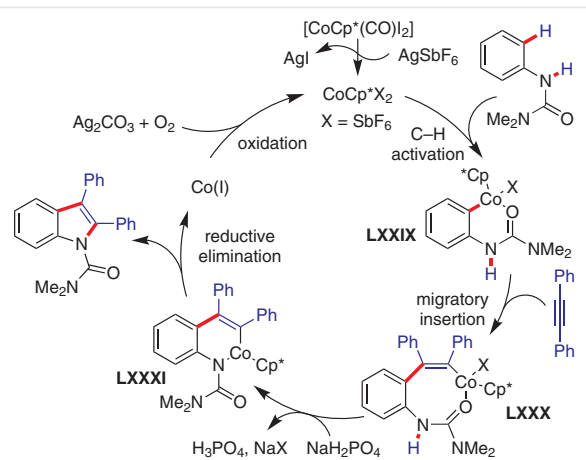

Scheme 69 The catalytic cycle for coupling of $\mathrm{N}$-arylureas with internal alkynes

A plausible mechanism for the reaction involves the generation of an active cationic $\mathrm{Co}$ (III) catalyst followed by irreversible $\mathrm{C}-\mathrm{H}$ bond activation affording six-membered metallacycle LXXIX. Coordination and migratory insertion of the alkyne generates the species LXXX, which upon elimination of HX yields intermediate LXXXI. Reductive elimination of the $\mathrm{C}-\mathrm{N}$ bond generates the desired indole along with $\mathrm{Co}(\mathrm{I})$, which is further oxidized by silver and oxygen to regenerate the active catalyst (Scheme 69).

A $\mathrm{Co}(\mathrm{III})$-catalyzed regioselective synthesis of indole motifs 129 was reported by Zhu's group (Scheme 70). ${ }^{62}$ Internal and terminal alkynes $\mathbf{1 2 8}$ were compatible with $\mathrm{N}$ aminoaniline derivatives $\mathbf{1 2 7}$ for cyclization. This strategy overcomes the drawbacks of earlier $\mathrm{Co}$ (III)-catalyzed redoxneutral methods for indole synthesis including high reaction temperatures, retention of bulky groups in the products and the generation of side products from external oxidants. The method provided the indole skeleton with diverse functional groups in moderate to excellent yields. Both electron-rich and electron-deficient substituents were tolerated, but steric effects played a dictating role in the reaction yield. 


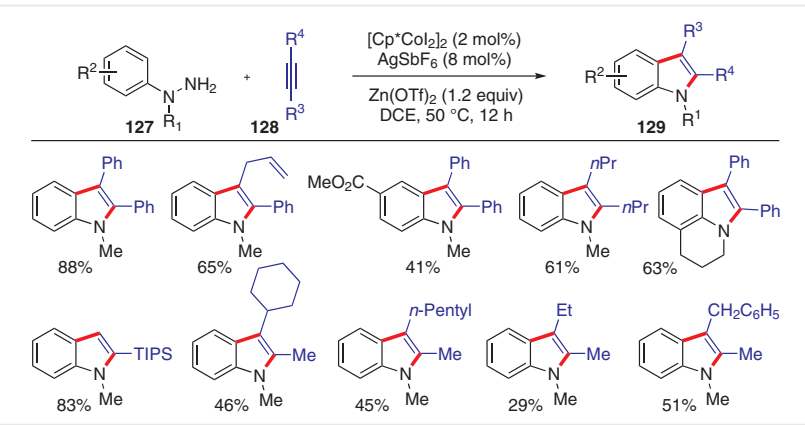

Scheme 70 Co(III)-catalyzed regioselective synthesis of indole motifs

The mechanism of the reaction involves the initial cobaltation of $\mathbf{1 2 7}$ and $\mathrm{Co}(\mathrm{II})$-promoted alkyne-allene isomerization. The insertion of allene LXXXIII via the internal $\mathrm{C}=\mathrm{C}$ bond into five-membered cobaltacycle LXXXII followed by cyclization provided the desired product (Scheme 71).

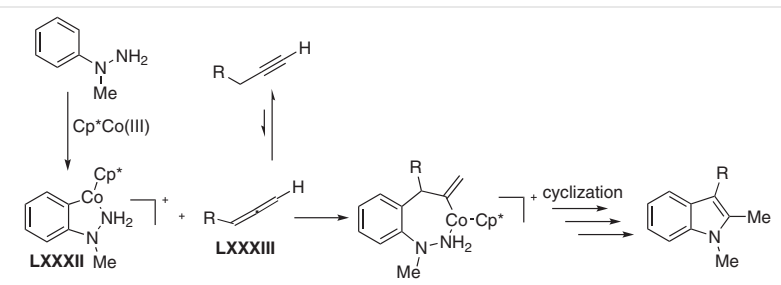

Scheme 71 Proposed mechanism for the reaction involving cyclization of alkynes with $\mathrm{N}$-aminoanilines

In 2016, Liu reported the synthesis of 3-amidoindoles 132 via $\mathrm{Rh}$ (III)-catalyzed cascade cyclization/electrophilic amidation of $o$-alkynylanilines $\mathbf{1 3 0}$ (Scheme 72). ${ }^{63}$ The authors used $N$-pivaloyloxyamides $\mathbf{1 3 1}$ as the electrophilic nitrogen source. The developed strategy provided 3-amidoindoles under mild conditions with good to excellent yields. Different functional groups present on both reactants were tolerated.

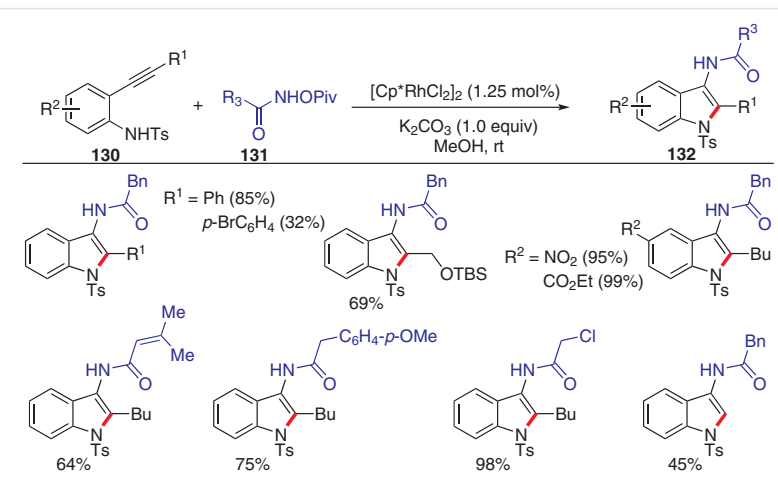

Scheme 72 Rh(III)-catalyzed cascade cyclization/electrophilic amidation of $o$-alkynylanilines
The proposed mechanism of the reaction involves the initial coordination of rhodium with $\mathbf{1 3 0}$. This makes the triple bond more susceptible to intramolecular nucleophilic attack by nitrogen and generates intermediate LXXXIV. The intermediate LXXXIV then reacts with 131 to furnish LXXXV through deprotonation of $\mathbf{1 3 1}$ and ligand exchange on LXXXIV. The expected product can be obtained from LXXXVI via two pathways (paths a and $b$ ). Path a, involves concerted $\mathrm{N}-\mathrm{O}$ bond cleavage with $\mathrm{C}-\mathrm{N}$ bond formation and regeneration of the catalyst. In path $\mathrm{b}$, reductive elimination followed by oxidative addition through pivaloyl group migration generates intermediate LXXXVI, which on protonolysis furnishes the indole product (Scheme 73).

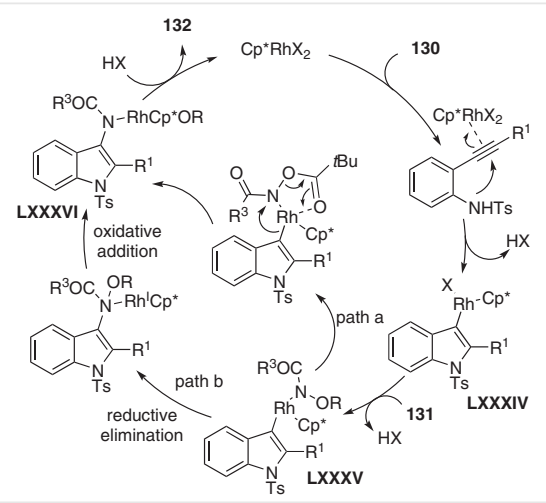

Scheme 73 Proposed mechanistic pathways

\section{Metal-Free 2,3-Disubstituted Indole Syn- thesis}

\subsection{N-Protected 2,3-Disubstituted Indole Synthesis}

Zhao et al. reported the synthesis of indoles $\mathbf{1 3 5}$ via intramolecular amination (Scheme 74) ${ }^{64}$ They used an organoselenium catalyst under mild conditions and obtained product yields of up to $99 \%$. Polar solvents were ineffective in this transformation and an electron-donating protecting group on the nitrogen disfavored the transformation, probably because the nitrogen of the substrate becomes less nucleophilic, hence preventing attack by the intermediate seleniranium ion. Only a trace amount of the product was obtained when using unsubstituted terminal alkenes. Different substituents on the aromatic ring of the substrate only slightly influenced the nitrogen nucleophilicity and hence the $\mathrm{C}-\mathrm{H}$ bond amination. Electron-donating $\mathrm{Me}$ and electron-withdrawing $\mathrm{CF}_{3}$ groups at the same position of the benzene ring gave the desired products in high yields (91\% and 93\%). 


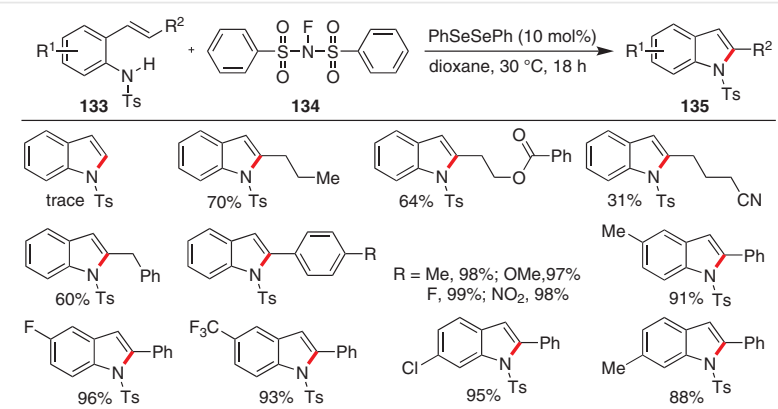

Scheme 74 Organocatalyst-catalyzed intramolecular synthesis of indoles

Otani and co-workers examined the Lewis acid- or base-promoted cycloisomerization of $\mathrm{N}$-imidoyl-2-alkynylanilines 136 with substituents such as alkyl or aryl. ${ }^{13}$ They described the formation of indole derivatives 137 via a 5-endo-dig cyclization mode (Scheme 75).

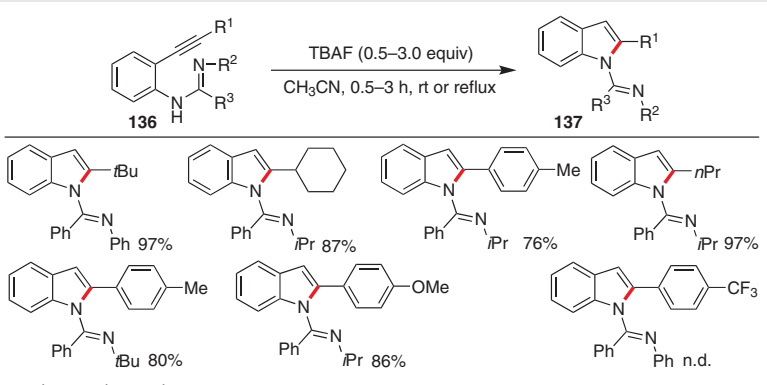

n.d. $=$ not detected

Scheme 75 Lewis acid/base-promoted cycloisomerization of $\mathrm{N}$-imidoyl-2-alkynylanilines

In 2012, Li's group reported the reaction of enaminones 138 with 2,2-dihydroxyindene-1,3-dione (139) on heating in acetic anhydride at $120^{\circ} \mathrm{C}$ under microwave irradiation conditions. Polyfunctionalized tetracyclic indeno[1,2-b]indoles 140 were obtained with different substitution patterns. ${ }^{65}$ This catalytic system showed excellent regioselectivity, short reaction times, mild conditions and good functional group tolerance at the $\mathrm{N}$-protected aryl ring of the enaminones $\mathbf{1 3 8}$ (Scheme 76).

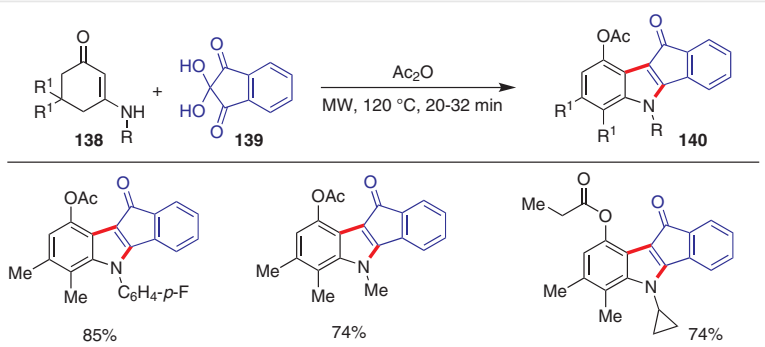

Scheme 76 Synthesis of indeno[1,2-b]indoles under microwave irradiation
In 2014, Youn's group reported a metal-free synthesis of substituted indoles 142 and 143 via $\mathrm{C}-\mathrm{H}$ amination of $N$-Ts2-alkenylanilines 141. ${ }^{6}$ This method showed broad substrate scope, good functional group tolerance and afforded good to excellent yields of the products. In the case of electron-withdrawing groups $\left[\mathrm{CO}_{2} n \mathrm{Bu}, \mathrm{CONMe}_{2}, \mathrm{CN}, \mathrm{PO}(\mathrm{OEt})_{2}\right]$ on the alkene moiety, no product was formed and mostly starting material was recovered. The reactions of $\beta, \beta$-disubstituted 2-alkenylanilines proceeded as expected to generate 2,3-disubstituted indoles, which showed that electronrich aryl groups migrated preferentially (Scheme 77).

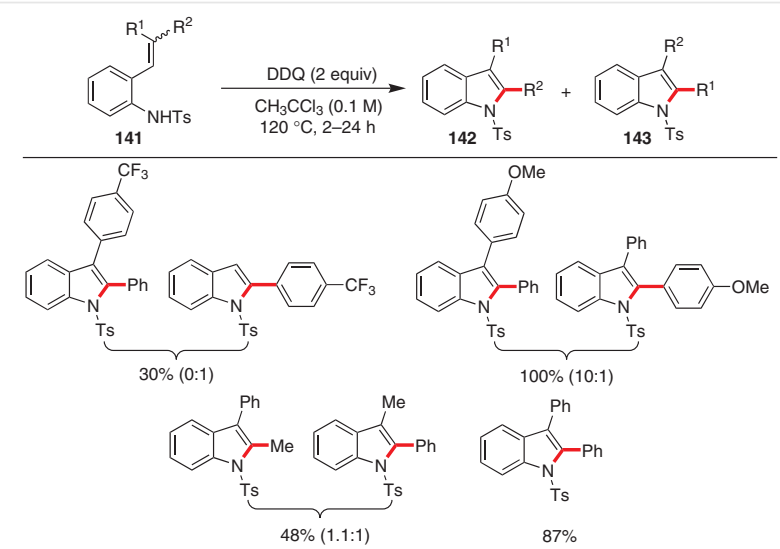

Scheme 77 Metal-free $\mathrm{C}-\mathrm{H}$ amination for the synthesis of indoles

The mechanism of the reaction was proposed after conducting a series of experiments. It was suggested that intramolecular nucleophilic attack by the $\mathrm{N}$-tosyl group of LXXXVII towards an olefin radical cation generates intermediate LXXXVIII. Oxidation of carbon radical of LXXXVIII gives the corresponding benzylic carbocation intermediate LXXXIX. This was followed by deprotonation to form the product via path $\mathrm{a}$, which is much faster than alternative path $\mathrm{b}$ (Scheme 78).

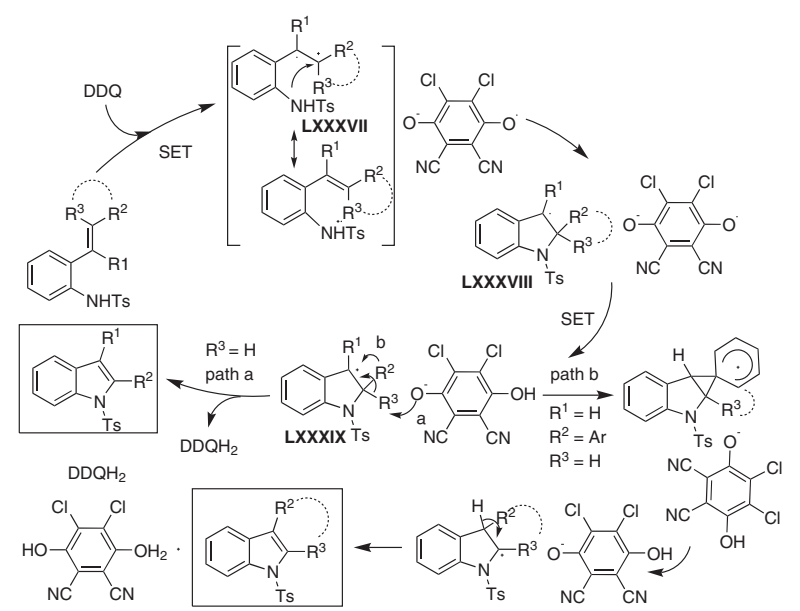

Scheme 78 Proposed mechanism for the metal-free indole synthesis 
In 2015, Deng's group reported the metal-free synthesis of indoles 145 from $N$-Ts-2-alkenylanilines 144 via a NISmediated cascade $\mathrm{C}-\mathrm{N}$ bond formation/aromatization. ${ }^{67}$ This reaction showed broad substrate scope and provided good to excellent yields under mild reaction conditions (Scheme 79).

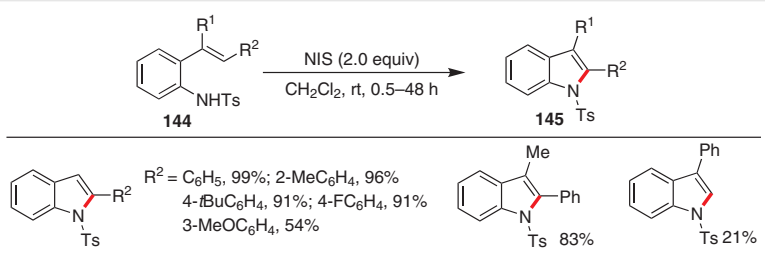

Scheme 79 NIS-mediated metal-free indole synthesis

Primarily, the iodonium ion intermediate $\mathbf{X C}$ is formed as NIS reacts with the substrate alkene, which undergoes intramolecular amination by the amino group to form indoline $\mathbf{X C I}$. This is followed by aromatization to form the indole product or 1,2-arylation occurs to form intermediate XCII, which after aromatization gives the final product (Scheme 80).
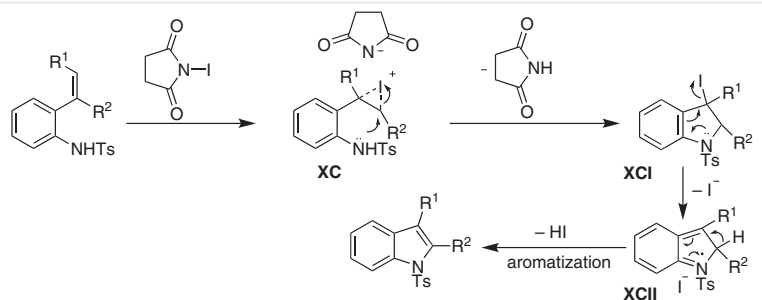

Scheme 80 Proposed mechanistic pathway for the metal-free indole synthesis

\subsection{N-Unprotected 2,3-Disubstituted Indole Syn- thesis}

König and co-workers reported the synthesis of functionalized indoles 148 in a tartaric acid-dimethylurea [L(+)-TA-DMU] melt under solvent- and catalyst-free conditions, starting from phenylhydrazine (146) and aldehydes/ketones 147. ${ }^{68}$ Examination of substrate scope showed that it tolerated sensitive functional groups such as $\mathrm{N}$-Boc, $\mathrm{N}$-Cbz and azides with excellent yields of products regioselectively. In addition, the method is environmentally benign and applicable for the synthesis of bioactive indoles (Scheme 81).

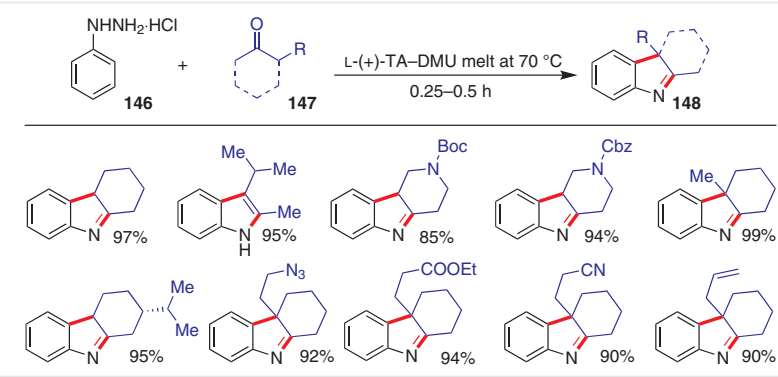

Scheme $\mathbf{8 1}$ Fischer indole synthesis in low melting mixtures

Zheng's group reported a one-pot procedure for the Fischer indole synthesis of compounds $\mathbf{1 5 1}$ from quinone monoketals 149 and aliphatic hydrazines 150 in chloroform with two equivalents of pyridine or under microwave conditions. ${ }^{69}$ The method showed good functional group tolerance, broad substrate scope and gave good to excellent yields of the indole products. An unsymmetrical hydrazine gave the cyclization product regioselectively (Scheme 82).

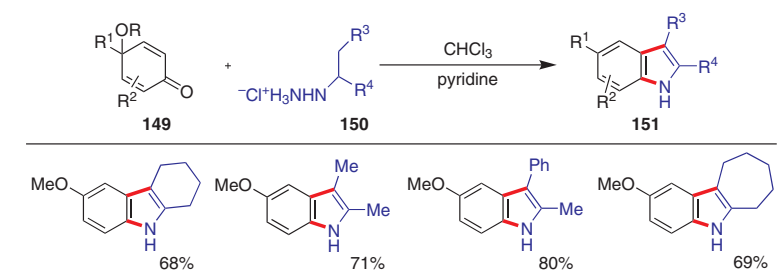

Scheme 82 Synthesis of indoles by condensation of quinone monoketals and aliphatic hydrazines

The condensation of quinone monoketals 149 with hydrazines 150 through 1,2-addition gave intermediate XCIII, which on dehydration gave intermediate XCIV. Subsequent aromatization gave the alkylaryldiazene $\mathbf{X C V}$, which underwent isomerization to afford intermediate XCVI. The indole product was obtained after elimination/cyclization process (Scheme 83).

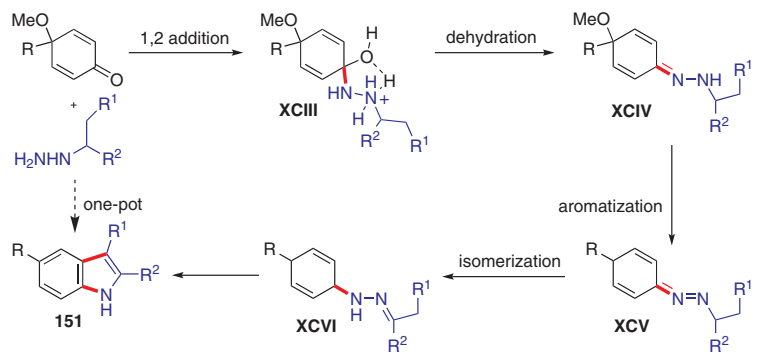

Scheme 83 Proposed mechanism for the Fischer indole synthesis of compounds 151 


\section{Applications}

Knochel and co-workers successfully synthesized indomethacin (2) and iprindole (5). Organozinc reagent 153 reacts with aryldiazonium salt $\mathbf{1 5 2}$ to produce the indole 154, which is further converted into indomethacin (2). ${ }^{48}$ Similarly, the reaction of cyclooctylzinc $\mathbf{1 5 5}$ with aryldiazonium salt 152 under standard reaction conditions provides indole 156, which was $\mathrm{N}$-alkylated to generate iprindole (5) (Scheme 84). ${ }^{48}$

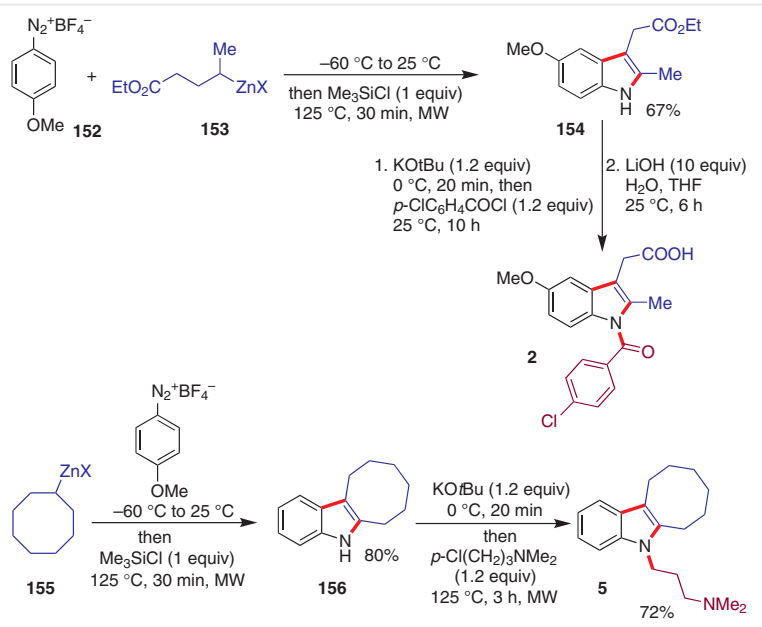

Scheme 84 The synthesis of indomethacin (2) and iprindole (5)

\section{Summary and Outlook}

In this review, we have described the recent progress in the field of the regioselective synthesis of indoles. We have discussed transition-metal-catalyzed methodologies via $\mathrm{C}-\mathrm{H}$ activation and have also described metal-free approaches for the synthesis of 2,3-disubstituted indoles with mechanisms. Some limitations of the classical Fisher indole synthesis were overcome by applying these new procedures. There is scope for the further development of new methodologies and for improvement of the reaction conditions. Future studies will provide new applications for the synthesis of complex bioactive molecules.

\section{Funding Information}

This work is supported by the Science and Engineering Research Board, India (EMR/2014/001023). R.K. and I.K. acknowledge UGC, New Delhi for Junior Research Fellowships.

\section{Acknowledgment}

The authors are grateful to the Director, CSIR-IHBT for providing necessary facilities. CSIR-IHBT communication no. for this publication is 4233.

\section{References}

(1) (a) Sundberg, R. J. Indoles 1996. (b) Kawasaki, T.; Higuchi, K. Nat. Prod. Rep. 2005, 22, 761. (c) d'Ischia, M.; Napolitano, A.; Pezzella, A. In Comprehensive Heterocyclic Chemistry III; Katritzky, A. R.; Ramsden, C. A.; Scriven, E. F. V.; Taylor, R. J. K., Eds.; Elsevier: Oxford, 2008, 353-388. (d) KochanowskaKaramyan, A. J.; Hamann, M. T. Chem. Rev. 2010, 110, 4489. (e) Xu, W.; Gavia, D. J.; Tang, Y. Nat. Prod. Rep. 2014, 31, 1474. (f) Ishikura, M.; Abe, T.; Choshi, T.; Hibino, S. Nat. Prod. Rep. 2015, 32, 1389 .

(2) (a) Chen, F.-E.; Huang, J. Chem. Rev. 2005, 105, 4671. (b) Boriskin, Y. S.; Leneva, I. A.; Pecheur, E. I.; Polyak, S. J. Curr. Med. Chem. 2008, 15, 997. (c) Shen, T. Y.; Windholz, T. B.; Rosegay, A.; Witzel, B. E.; Wilson, A. N.; Willett, J. D.; Holtz, W. J.; Ellis, R. L.; Matzuk, A. R.; Lucas, S.; Stammer, C. H.; Holly, F. W.; Sarett, L. H.; Risley, E. A.; Nuss, G. W.; Winter, C. A. J. Am. Chem. Soc. 1963, 85, 488. (d) Augelli-Szafran, C. E.; Jaen, J. C.; Moreland, D. W.; Nelson, C. B.; Penvose-Yi, J. R.; Schwarz, R. D. Bioorg. Med. Chem. Lett. 1998, 8, 1991. (e) Rice, L. M.; Hertz, E.; Freed, M. E. J. Med. Chem. 1964, 7, 313. (f) Baxter, B. L.; Gluckman, M. I. Nature 1969, 223, 750. (g) Chen, H.; Eberlin, L. S.; Nefliu, M.; Augusti, R.; Cooks, R. G. Angew. Chem. Int. Ed. 2008, 47, 3422.

(3) Sundberg, R. J. In Comprehensive Heterocyclic Chemistry; Katritzky, A. R.; Rees, C. W., Eds.; Pergamon: Oxford, 1984, 313.

(4) (a) Song, J. J.; Reeves, J. T.; Fandrick, D. R.; Tan, Z.; Yee, N. K.; Senanayake, C. H. ARKIVOC 2010, (i), 390. (b) Cacchi, S.; Fabrizi, G. Chem. Rev. 2011, 111, PR215. (c) Guo, T.; Huang, F.; Yu, L.; Yu, Z. Tetrahedron Lett. 2015, 56, 296.

(5) Maity, S.; Zheng, N. Angew. Chem. Int. Ed. 2012, 51, 9562.

(6) Wei, Y.; Deb, I.; Yoshikai, N. J. Am. Chem. Soc. 2012, 134, 9098.

(7) Nanjo, T.; Tsukano, C.; Takemoto, Y. Org. Lett. 2012, 14, 4270.

(8) Wang, Y.; Liu, L.; Zhang, L. Chem. Sci. 2013, 4, 739.

(9) Anxionnat, B.; Gomez Pardo, D.; Ricci, G.; Rossen, K.; Cossy, J. Org. Lett. 2013, 15, 3876.

(10) Kiruthika, S. E.; Perumal, P. T. Org. Lett. 2014, 16, 484.

(11) Besandre, R.; Jaimes, M.; May, J. A. Org. Lett. 2013, 15, 1666.

(12) Guo, T.; Jiang, Q.; Yu, Z. Org. Chem. Front. 2015, 2, 1361.

(13) Otani, T.; Jiang, X.; Cho, K.; Araki, R.; Kutsumura, N.; Saito, T. Adv. Synth. Catal. 2015, 357, 1483.

(14) Sayyad, M.; Nanaji, Y.; Ghorai, M. K. J. Org. Chem. 2015, 80, 12659.

(15) Gschwend, H. W.; Rodriguez, H. R. Org React. 1979, $26,1$.

(16) Ghorai, M. K.; Sayyad, M.; Nanaji, Y.; Jana, S. Chem. Eur. J. 2015, $10,1480$.

(17) Zardi, P.; Savoldelli, A.; Carminati, D. M.; Caselli, A.; Ragaini, F.; Gallo, E. ACS Catal. 2014, 4, 3820.

(18) Choi, I.; Chung, H.; Park, J. W.; Chung, Y. K. Org. Lett. 2016, 18, 5508.

(19) Ito, Y.; Ueda, M.; Takeda, N.; Miyata, O. Chem. Eur. J. 2016, 22, 2616.

(20) Taber, D. F.; Tirunahari, P. K. Tetrahedron 2011, 67, 7195.

(21) Cacchi, S.; Fabrizi, G.; Goggiamani, A.; Perboni, A.; Sferrazza, A.; Stabile, P. Org. Lett. 2010, 12, 3279.

(22) Brand, J. P.; Chevalley, C.; Waser, J. Beilstein J. Org. Chem. 2011, 7, 565.

(23) Nallagonda, R.; Rehan, M.; Ghorai, P. Org. Lett. 2014, 16, 4786.

(24) Zhou, B.; Yang, Y.; Tang, H.; Du, J.; Feng, H.; Li, Y. Org. Lett. 2014, 16, 3900.

(25) Panferova, L. I.; Smirnov, V. O.; Levin, V. V.; Kokorekin, V. A.; Struchkova, M. I.; Dilman, A. D. J. Org. Chem. 2017, 82, 745.

(26) Miao, B.; Li, S.; Li, G.; Ma, S. Org. Lett. 2016, 18, 2556. 
(27) Porcheddu, A.; Mura, M. G.; De Luca, L.; Pizzetti, M.; Taddei, M. Org. Lett. 2012, 14, 6112.

(28) Müller, S.; Webber, M. J.; List, B. J. Am. Chem. Soc. 2011, 133, 18534.

(29) Zhan, F.; Liang, G. Angew. Chem. Int. Ed. 2013, 52, 1266.

(30) Liu, B.; Song, C.; Sun, C.; Zhou, S.; Zhu, J. J. Am. Chem. Soc. 2013, 135,16625

(31) Lu, B. Z.; Wei, H.-X.; Zhang, Y.; Zhao, W.; Dufour, M.; Li, G.; Farina, V.; Senanayake, C. H. J. Org. Chem. 2013, 78, 4558.

(32) Zhang, M.; Xie, F.; Wang, X.; Yan, F.; Wang, T.; Chen, M.; Ding, Y. RSC Adv. 2013, 3, 6022.

(33) Jana, N.; Nguyen, Q.; Driver, T. G. J. Org. Chem. 2014, 79, 2781.

(34) Lim, B.-Y.; Jung, B.-E.; Cho, C.-G. Org. Lett. 2014, 16, 4492.

(35) Chen, J.; He, L.; Natte, K.; Neumann, H.; Beller, M.; Wu, X.-F. Adv. Synth. Catal. 2014, 356, 2955.

(36) Ye, K.-Y.; Dai, L.-X.; You, S.-L. Chem. Eur. J. 2014, 20, 3040.

(37) Lin, H.; Li, S.-S.; Dong, L. Org. Biomol. Chem. 2015, 13, 11228.

(38) Sagadevan, A.; Ragupathi, A.; Hwang, K. C. Angew. Chem. Int. Ed. 2015, 54, 13896.

(39) (a) Sagadevan, A.; Ragupathi, A.; Lin, C.-C.; Hwu, J. R.; Hwang, K. C. Green Chem. 2015, 17, 1113. (b) Mylnikov, V. S. Zh. Strukt. Khim. 1974, 15, 244.

(40) (a) Majek, M.; Jacobi von Wangelin, A. Angew. Chem. Int. Ed. 2013, 52, 5919. (b) Yam, V. W.-W.; Lo, K. K.-W.; Wong, K. M.-C. J. Organomet. Chem. 1999, 578, 3.

(41) Díez-González, S.; Correa, A.; Cavallo, L.; Nolan, S. P. Chem. Eur.J. 2006, 12, 7558.

(42) Zhang, G.; Miao, J.; Zhao, Y.; Ge, H. Angew. Chem. Int. Ed. 2012, $51,8318$.

(43) Zhou, Z.; Liu, G.; Chen, Y.; Lu, X. Adv. Synth. Catal. 2015, 357, 2944.

(44) Yan, H.; Wang, H.; Li, X.; Xin, X.; Wang, C.; Wan, B. Angew. Chem. Int. Ed. 2015, 54, 10613.

(45) Patureau, F. W.; Besset, T.; Kuhl, N.; Glorius, F. J. Am. Chem. Soc. 2011, 133, 2154.

(46) Kim, T.; Kim, K. Tetrahedron Lett. 2010, 51, 868.

(47) Wang, C.; Huang, Y. Org. Lett. 2013, 15, 5294.

(48) Haag, B. A.; Zhang, Z.-G.; Li, J.-S.; Knochel, P. Angew. Chem. Int. Ed. 2010, 49, 9513.
(49) Jiang, H.; Gao, S.; Xu, J.; Wu, X.; Lin, A.; Yao, H. Adv. Synth. Catal. 2016, 358, 188.

(50) Würtz, S.; Rakshit, S.; Neumann, J. J.; Dröge, T.; Glorius, F. Angew. Chem. Int. Ed. 2008, 47, 7230.

(51) Shi, Z.; Zhang, C.; Li, S.; Pan, D.; Ding, S.; Cui, Y.; Jiao, N. Angew. Chem. Int. Ed. 2009, 48, 4572.

(52) Qi, Z.; Yu, S.; Li, X. Org. Lett. 2016, 18, 700.

(53) Wu, C.-J.; Meng, Q.-Y.; Lei, T.; Zhong, J.-J.; Liu, W.-Q.; Zhao, L.M.; Li, Z.-J.; Chen, B.; Tung, C.-H.; Wu, L.-Z. ACS Catal. 2016, 6, 4635.

(54) Zhang, Z.; Jiang, H.; Huang, Y. Org. Lett. 2014, 16, 5976.

(55) Miyanaga, W.; Sugiki, M.; Ejima, C.; Tokumasu, M.; Yoshida, T. WO2014/003158 A1, 2014.

(56) Layek, M.; Reddy, M. A.; Dhanunjaya Rao, A. V.; Alvala, M.; Arunasree, M. K.; Islam, A.; Mukkanti, K.; Iqbal, J.; Pal, M. Org. Biomol. Chem. 2011, 9, 1004.

(57) Ding, M.; He, F.; Hudyma, T. W.; Zheng, X.; Poss, M. A.; Kadow, J. F.; Beno, B. R.; Rigat, K. L.; Wang, Y.-K.; Fridell, R. A.; Lemm, J. A.; Qiu, D.; Liu, M.; Voss, S.; Pelosi, L. A.; Roberts, S. B.; Gao, M.; Knipe, J.; Gentles, R. G. Bioorg. Med. Chem. Lett. 2012, 22, 2866.

(58) (a) Zhao, D.; Shi, Z.; Glorius, F. Angew. Chem. Int. Ed. 2013, 52, 12426. (b) Xu, L.; Zhu, Q.; Huang, G.; Cheng, B.; Xia, Y. J. Org. Chem. 2012, 77, 3017.

(59) Zhou, S.; Wang, J.; Zhang, F.; Song, C.; Zhu, J. Org. Lett. 2016, 18 , 2427.

(60) Li, D. Y.; Chen, H. J.; Liu, P. N. Org. Lett. 2014, 16, 6176.

(61) Zhang, Z.-Z.; Liu, B.; Xu, J.-W.; Yan, S.-Y.; Shi, B.-F. Org. Lett. 2016, 18,1776 .

(62) Zhou, S.; Wang, J.; Wang, L.; Chen, K.; Song, C.; Zhu, J. Org. Lett. 2016, 18, 3806.

(63) Hu, Z.; Tong, X.; Liu, G. Org. Lett. 2016, 18, 2058.

(64) Zhang, X.; Guo, R.; Zhao, X. Org. Chem. Front. 2015, 2, 1334.

(65) Jiang, B.; Li, Q.-Y.; Tu, S.-J.; Li, G. Org. Lett. 2012, 14, 5210.

(66) Jang, Y. H.; Youn, S. W. Org. Lett. 2014, 16, 3720.

(67) Li, Y.-L.; Li, J.; Ma, A.-L.; Huang, Y.-N.; Deng, J.J. Org. Chem. 2015, $80,3841$.

(68) Gore, S.; Baskaran, S.; König, B. Org. Lett. 2012, 14, 4568.

(69) Zhang, J.; Yin, Z.; Leonard, P.; Wu, J.; Sioson, K.; Liu, C.; Lapo, R.; Zheng, S. Angew. Chem. Int. Ed. 2013, 52, 1753. 